\title{
Influences of Nitrogen Flow Rate on Microstructure, Mechanical and Tribological Properties of WCN Coatings Deposited by HiPIMS
}

\author{
Weifeng He ${ }^{1}$, Yuhui Yang ${ }^{1}$, Shuqi Huang ${ }^{2}$, Shuyu Fan ${ }^{2}$, Min Hu ${ }^{3}$, Yongchao Wang ${ }^{3,4} \mathbb{D}$, Wei Xu $^{2, *}$ \\ and Lei Wang $2,5, * \mathbb{D}$
}

check for

updates

Citation: He, W.; Yang, Y.; Huang, S.; Fan, S.; Hu, M.; Wang, Y.; Xu, W.; Wang, L. Influences of Nitrogen Flow Rate on Microstructure, Mechanical and Tribological Properties of WCN Coatings Deposited by HiPIMS Coatings 2021, 11, 481. https:// doi.org/10.3390/coatings11040481

Received: 26 March 2021

Accepted: 17 April 2021

Published: 20 April 2021

Publisher's Note: MDPI stays neutral with regard to jurisdictional claims in published maps and institutional affiliations.

Copyright: (C) 2021 by the authors Licensee MDPI, Basel, Switzerland. This article is an open access article distributed under the terms and conditions of the Creative Commons Attribution (CC BY) license (https:// creativecommons.org/licenses/by/ $4.0 /)$
1 School of Mechanical Engineering, Dongguan University of Technology, Dongguan 523808, China; dgutweifenghe@163.com (W.H.); yangyuhui8911@163.com (Y.Y.)

2 The Key Lab of Guangdong for Modern Surface Engineering Technology, National Engineering Laboratory for Modern Materials Surface Engineering Technology, Institute of New Materials, Guangdong Academy of Sciences, Guangzhou 510650, China; huangshuqi@gdinm.com (S.H.); fsy19970822@163.com (S.F.)

3 Synergy Innovation Institute for Modern Industries of Guangdong University of Technology, Dongyuan 517500, China; nghsky2006@163.com (M.H.); chriswang1225@foxmail.com (Y.W.)

4 School of Electromechanical Engineering, Guangdong University of Technology, Guangzhou 510006, China

5 School of Materials and Energy, Guangdong University of Technology, Guangzhou 510006, China

* Correspondence: xuwei@gdinm.com (W.X.); 406wanglei@buaa.edu.cn (L.W.)

\begin{abstract}
Tungsten carbide (WC) and Tungsten carbonitride (WCN) coatings are deposited by reactive high-power impulse magnetron sputtering (HiPIMS) with various nitrogen gas flow rates. The characteristics of discharge current and plasma optical emission of HiPIMS are recorded by oscilloscope (OSC) and optical emission spectroscopy (OES). The results exhibit that the peak discharge currents and the intensities of optical emission spectra lines are significantly influenced by the addition of nitrogen. The elemental concentration, microstructure, mechanical and tribological properties in ambient temperature and high temperature of deposited coatings are investigated by a wide variety of techniques such as energy dispersive spectroscopy (EDS), X-ray diffraction (XRD), nano-indentation measurement, scanning electron microscope (SEM), atomic force microscopy (AFM), X-ray photoelectron spectroscopy (XPS), and ball-on-disk tribometer. The results show that WC/WCN coatings with different microstructures, mechanical properties and tribological properties have been produced by controlling the flow rate of $\mathrm{N}_{2}$. Meanwhile, with the $\mathrm{N}_{2}$ flow rate increasing from $0 \mathrm{sccm}$ to $24 \mathrm{sccm}$, (101) diffraction peak shifts to low angle. Moreover, (102) and (110) peaks' intensities and the angle of (101) peak of $\beta-\mathrm{W}_{2} \mathrm{C}$ phase of the deposited WCN coatings decrease and disappear, and the average grain size decreases from $8.9 \mathrm{~nm}$ to $6.4 \mathrm{~nm}$. XPS results show that the intensities of $\mathrm{C}=\mathrm{N}, \mathrm{W}-\mathrm{N}, \mathrm{W}-\mathrm{C}-\mathrm{N}$, and $\mathrm{N}-\mathrm{O}$ peaks increase while the intensity of $\mathrm{C}-\mathrm{W}$ peak decreases. The deposited coatings change from slight columnar type to a typically dense and featureless structure, and the surface roughness decreases from Ra $11.6 \mathrm{~nm}$ at $0 \mathrm{sccm}$ to Ra $5.7 \mathrm{~nm}$ at $24 \mathrm{sccm}$. The variation of nitrogen flow also plays a role in the mechanical properties of the coatings. It is found that the maximum hardness and elastic modulus of $35.6 \mathrm{GPa}$ and $476.5 \mathrm{GPa}$ appear at $16 \mathrm{sccm} \mathrm{N}_{2}$ flow rate. The results of wear tests demonstrate the addition of nitrogen slightly deteriorates tribological properties at room temperature $\left(25^{\circ} \mathrm{C}\right)$, but can remarkably improve tribological properties at high temperature $\left(400{ }^{\circ} \mathrm{C}\right)$ of $\mathrm{WC} / \mathrm{WCN}$ coatings deposited with an appropriate flow rate of nitrogen.
\end{abstract}

Keywords: WCN; HiPIMS; discharge characteristics; mechanical properties; tribological performance

\section{Introduction}

Owing to a lot of excellent properties such as high hardness, low friction coefficient, good chemical stability and high wear resistance, tungsten carbide (WC) coatings serving as one of the protective coatings for mechanical components and cutting tools have attracted increasing critical attention and become a research focus in modern manufacturing 
industry [1-5]. However, the oxidation of graphite phase [6,7] in WC or W containing diamond-like carbon coatings (W-DLC, WC-DLC) above $400{ }^{\circ} \mathrm{C}$ in the air have limitations in practical applications, such as high-speed cutting, dry machining, and high-speed rotating [8]. The oxidation of carbon in WC coatings would give rise to accelerated material losses, deteriorated tribological properties and a shortened service life. So, enhancing its wear resistance at high temperatures is of vital importance to improve the performance and prolong the lifetime of WC coatings.

Doping Nitrogen is quite common and promising to enhance properties of nanocomposite coatings. For instance, through making use of high power impulse magnetron sputtering (HiPIMS) technique Shen et al. [9] deposited diamond like carbon films on AISI 304L austenitic stainless using $\mathrm{Ar}$ and $\mathrm{N}_{2}$ as precursors at room temperature. The results showed that the Nitrogen-doped diamond like carbon coating exhibited better tribocorrosion properties. Bootkul, D et al. [10] synthesized nitrogen doped tetrahedral amorphous carbon (ta-C:N) using the filtered cathodic vacuum arc (FCVA) technique. Measurement results showed that intentionally doping with nitrogen reduced the carbon sp3 content, hardness but increased the surface roughness and the critical load. According to Corona-Gomez's experiments [11], Nitrogen doped DLC (NDLC) was successfully deposited on CoCrMo by ICP-CVD and the effect of nitrogen doping on the film adhesion was investigated by Rockwell $C$ indentation. The results show that nitrogen doping can improve the film adhesion and the wear resistance significantly. Ju, Hongbo et al. [12] added non-metal nitrogen into the molybdenum disulfide solid self-lubricant film using RF magnetron sputtering system and the influence of nitrogen on the microstructure, mechanical, oxidation resistance and tribological properties of the Mo-S-N composite films were investigated. The results show that all Mo-S-N films exhibit higher hardness, oxidation resistance temperature and tribological properties at room temperature, 200 , and $400{ }^{\circ} \mathrm{C}$.

In conclusion, the addition of nitrogen into protective coatings proves to be effective for their properties improvement, such as wear resistance, corrosion resistance, oxidation resistance, adhesion strength and tribological property. The study on WCN coatings is relatively few, in comparison with WC coatings. Besides this, the mechanical properties and the influence of nitrogen at room temperature and high temperature of WCN films have not been studied systematically. In this study WCN coatings are deposited by reactive HiPIMS at acetylene/argon $\left(\mathrm{C}_{2} \mathrm{H}_{2} / \mathrm{Ar}\right)$ atmosphere with doping different nitrogen content. The elemental concentration, microstructure, mechanical properties, and tribological properties at ambient temperature and high temperature are investigated to examine the effects of the addition of nitrogen. A comparison of the results with those WCN coatings for a reference pure WC sample is also provided.

\section{Experiment Details}

\subsection{Coatings Preparation}

WC and WCN coatings are deposited on $\mathrm{Si}(100)$ wafers and YT 15 cemented carbide (WC-10 wt.\%. Co) disks by using an industrial PVD deposition equipment with hexagonal vacuum chamber, which is about $800 \mathrm{~mm}$ high with a side length of $600 \mathrm{~mm}$. The deposition equipment is equipped in a closed field magnetron sputtering with four cathodes through direct water-cooling. One cathode is equipped with a rectangular $\mathrm{W}_{70} \mathrm{C}_{30}$ alloy $\left(565 \times 115 \mathrm{~mm}^{2}\right)$ and others are installed with blind flanges in this study. Detailed description of the experimental setup is reported in our previous papers [13,14]. Before deposition, the cemented carbide substrates are polished using a metallographic polishing machine (FMP1000Z, Testin Co.,LTD. Dongguan, China) and cleaned by acetone and alcohol in ultrasonic bath for $15 \mathrm{~min}$ each. Then the substrates are mounted on a rotary sample holder with a $10 \mathrm{~cm}$ distance parallel to the target surface. After that, the chamber is evacuated to below $4.0 \times 10^{-4} \mathrm{~Pa}$. The $\mathrm{W}_{70} \mathrm{C}_{30}$ target then is cleaned in $\mathrm{Ar}$ with the discharge pressure of $0.8 \mathrm{~Pa}$ for $20 \mathrm{~min}$. In order to remove the contaminations and oxide layer on the surface, the substrates are also sputter-cleaned by using the glow discharge of Ar at $-800 \mathrm{~V}$ for $25 \mathrm{~min}$. 
The HiPIMS power supply for WC target is operated in constant voltage mode and the peak target voltage is maintained at $-800 \mathrm{~V}$. The voltage before pulse kept at $-400 \mathrm{~V}$ and drops after the discharge to $-200 \mathrm{~V}$ then rise up to $-400 \mathrm{~V}$ during the pulse off time, this design is in order to make the target easier to glow and to improve sputtering efficiency. During the deposition, the pulse duration and frequency of the power supply are $100 \mu \mathrm{s}$ and $200 \mathrm{~Hz}$, corresponding to duty cycles at $2 \%$. The bias voltage of substrates is fixed at $-80 \mathrm{~V}$. The deposition temperature is maintained at $150{ }^{\circ} \mathrm{C}$. The deposition time of all the WC/WCN coatings is fixed at $30 \mathrm{~min}$. The only variable is the addition flow rate of nitrogen. Nitrogen added to the constant Ar flow in $8 \mathrm{sccm}$ increments ranges from $0 \mathrm{sccm}$ to $24 \mathrm{sccm}$. The working pressure increases from $0.8 \mathrm{~Pa}$ to $0.92 \mathrm{~Pa}$ by adding nitrogen. The sputtering details and deposition parameters are listed in Table 1.

Table 1. Details and deposition parameters of sputtering.

\begin{tabular}{cc}
\hline Parameter & Value \\
\cline { 2 - 2 } & Samples (0 Sccm/8 Sccm/16 Sccm/24 Sccm) \\
\hline Target-Substrate Distance $(\mathrm{cm})$ & 10 \\
Temperature $\left({ }^{\circ} \mathrm{C}\right)$ & 150 \\
Deposition Pressure $(\mathrm{Pa})$ & 0.8 \\
$\mathrm{~N}_{2}$ Pressure $(\mathrm{Pa})$ & $0.0 / 0.04 / 0.08 / 0.12$ \\
Total Deposition Time $(\mathrm{min})$ & 30 \\
Substrate Bias Voltage $(\mathrm{V})$ & -80 \\
Pulse Width $(\mu \mathrm{\mu s})$ & 100 \\
Repetition frequency $(\mathrm{Hz})$ & 200 \\
Pulse Negative Voltage $(\mathrm{V})$ & -800 \\
Peak Discharge Current $(\mathrm{A})$ & $61.5 / 70.9 / 77.6 / 61.6$ \\
\hline
\end{tabular}

\subsection{Characterization}

The target voltage and target current are measured by a high voltage differential probe and a passive probe, and recorded by a digital oscilloscope (OSC, RTE1052, Rhode \& Schwartz, Munich, Germany). An optical emission spectrometer (OES, Ocean Optics Ltd., Dunedin, FL, USA, HR4000CG-UV-NIR) positioned in front of observation window is used to monitor the plasma species and relative quantities at various flow rates of nitrogen during deposition. The collimated optical fiber port was installed vertical to the target surface with a distance of $30 \mathrm{~cm}$. Schematic diagram of the deposition apparatus and OES diagnostic experimental set-up is shown in Figure 1. In order to reduce errors of the collected plasma discharge characteristics, the integral time was set as $100 \mathrm{~ms}$, and every 10 plasma pulses were summed and averaged to obtained presented spectra.

Thickness, surface and cross-sectional morphology of the obtained WC/WCN coatings are evaluated by scanning electron microscopy (SEM, Zeiss, SUPRA55, Carl Zeiss Co.,LTD, Aalen, Germany). Energy dispersive X-ray spectroscopy (EDS) is used to determine the chemical compositions of the coatings and the wear tracks. The surface morphology and roughness with an area size of $10 \times 10 \mu \mathrm{m}^{2}$ are evaluated by atomic force microscopy (AFM, Veeco, Bruker-ICON, Bruker Co.,LTD, Billerica, MA, USA) by using probe-scanning mode.

The analyses of crystallinity and microstructures are carried out via grazing incidence X-ray diffractometry (GIXRD, D/Max 2500/PC, Rigaku Industrial Corporation, Takatsukishi, Osaka, Japan) with an incident angle of $2.0^{\circ}$ and a scanning speed of $0.05^{\circ} / \mathrm{s}$. X-ray diffractograms of WC and WCN coatings are collected at angles between $10^{\circ}$ and $90^{\circ}$ with a $\mathrm{Cu} \mathrm{K} \alpha$ source $(\mathrm{K} \gamma=1.5406 \AA)$. X-ray photoelectron spectra (XPS, Ulvac-Phi Inc, PHI Quantera II, ULVAC-PHI Corporation, Chigasaki, Kanagawa, Japan) equipped with a mono-chromatic $\mathrm{Al} \mathrm{K} \alpha$ radiation at the $1486.7 \mathrm{eV}$ source is used to analyze the chemical compositions and bonding state of the deposited coatings. The XPS measurement is performed in constant analyzer energy mode with a $20-\mathrm{eV}$ pass energy (take of angle: $45^{\circ}$, step size: $0.1 \mathrm{eV}$ ) for high-resolution spectra at a base pressure of $4 \times 10^{-8} \mathrm{~Pa}$. Prior to the analysis, the samples are pre-sputtered by Ar ion bombardment for $180 \mathrm{~s}$ to remove surface 
contamination. All the XPS spectra fittings are performed following a Shirley background subtraction with the Gaussian-Lorentzian peak shape.

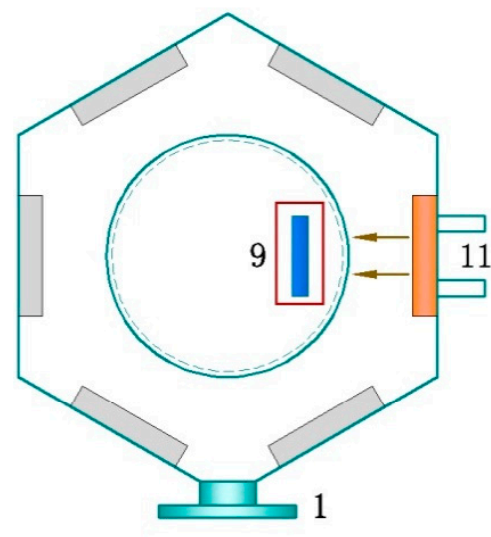

1 Inspection Windows

2 Planetary Table

3 Holder

4 DC Bias Supply for Table

5 HiPIMS Power Supply 6 Pumped Vacuum System

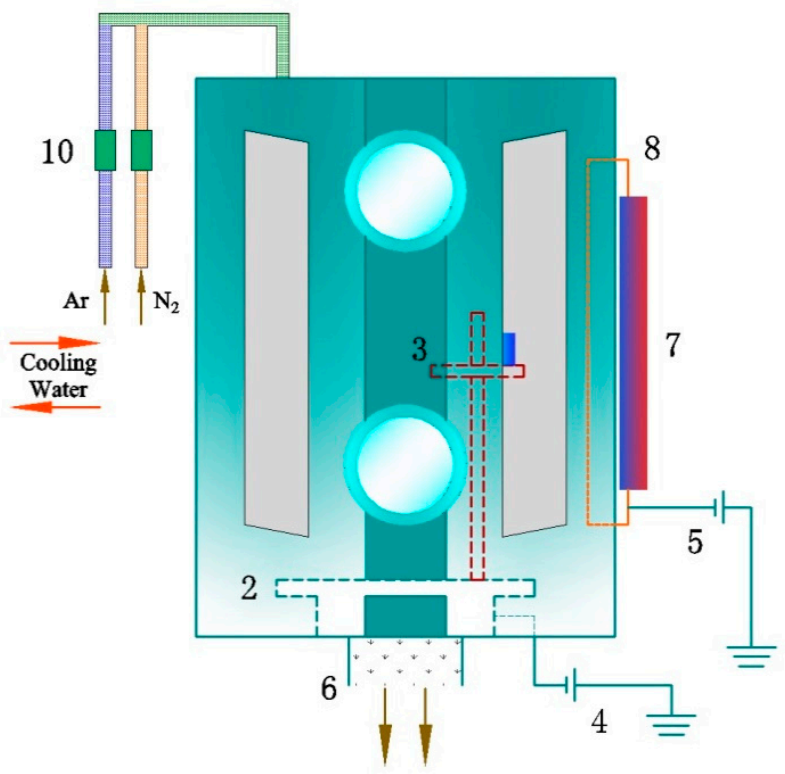

7 Magnetron

8 Tungsten Carbide Target

9 Substrate

10 Mass Flow Control

11 Cooling Water System

Figure 1. Schematic of the deposition apparatus.

Nanoindentation measurements are carried out via a nanoindenter (Nano-Indentor G200, Agilent, KLA-Tencor Corporation, Milpitas, CA, USA) equipped with a Berkovich diamond tip in continuous stiffness measurement (CSM) mode. The maximum load, loading resolution and rate are chosen as $10 \mathrm{mN}, 50 \mathrm{nN}$ and $0.23 \mathrm{mN} / \mathrm{s}$. To avoid the influence of indentation size effects and the substrate, the maximum indentation depth of $300 \mathrm{~nm}(<10 \%$ of the coating's thickness) is selected. Each sample is tested for 10 times to minimize possible errors. The hardness $(\mathrm{H})$ and Young's modulus (E) are evaluated by indentation curves according to Oliver and Pharr's equation [15].

To investigate tribological properties of the deposited coatings, friction and wear tests are performed in a high-temperature ball-on-disk tribometer (Bruker, UMT-3, Bruker Co., LTD, Billerica, MA, USA) at room temperature of about $25^{\circ} \mathrm{C}$ and elevated temperature of $400{ }^{\circ} \mathrm{C}$ with initial relative humidity of $60 \%$ respectively. The applied load is set as $8 \mathrm{~N}$, the sliding speed at $0.1 \mathrm{~m} / \mathrm{s}$ and the sliding radius at $4 \mathrm{~mm} . \mathrm{Al}_{2} \mathrm{O}_{3}$ balls of $6 \mathrm{~mm}$ diameter are selected as the counterpart due to its chemical inertness and do not react with the coating material. The wear tests are operated in rotating mode with the sliding time of $3600 \mathrm{~s}$. Wear tracks on coating surface are observed by SEM and laser confocal scanning microscope (LCSM, OLYMPUS, OLS4100, Olympus Corporation, Shinjuku, Tokyo, Japan). The normalized wear rates $\left(\mathrm{mm}^{3} / \mathrm{Nm}\right)$ are calculated by cross-sectional profiles of diskwear track obtained with the surface contact profilometer (Bruker, DEKTAK XT, Bruker Co., LTD, Billericacity, MA, USA).

\section{Results and Discussion}

\subsection{Plasma Discharge Characteristics}

Figure 2 presents the evolution of the target voltage and discharge current waveforms with the nitrogen gas flow during the HiPIMS process. It can be seen that with the increase 
of the nitrogen gas flow rate from 0 to $24 \mathrm{sccm}$, the target voltage remains stable (Figure 2a) while the peak discharge current first rises up from $61.5 \mathrm{~A}$ at $0 \mathrm{sccm}$ to $77.6 \mathrm{~A}$ at $16 \mathrm{sccm}$, then decreases to $61.6 \mathrm{~A}$ at $24 \mathrm{sccm}$ (Figure 2b). The changes in discharge current with increasing nitrogen flow rate could be explained as follows. Target current is directly proportional to the quantity of particles participating in sputtering. The total working pressure increases with increasing inflow nitrogen, which leads to more collision and produces more ions [15]. These producing ions accelerate toward the target under electric field, which causes more ions bombardments resulting in increased discharge current and higher materials sputtering rates. However, as the nitrogen flow rates further increases, exceeding the rate of consumption, excessive reactive gas will lead to target poisoning and form a stoichiometric film at WC target surface. The resistance of the formed compound film is much higher that of pure alloy target, which leads to the accumulation of positive charge on target surface and preventing further ion-bombardment [16]. This results in decreases in the number of sputtered particles and a lower peak discharge current [17]. Moreover, with the increasing quantities of gas molecule, the collisions become more and more frequent, which causes a much shorter mean free path and insufficient kinetic energies of the colliding particles. This, in turn, leads to decreases of sputtered particles and peak discharge current $[18,19]$.
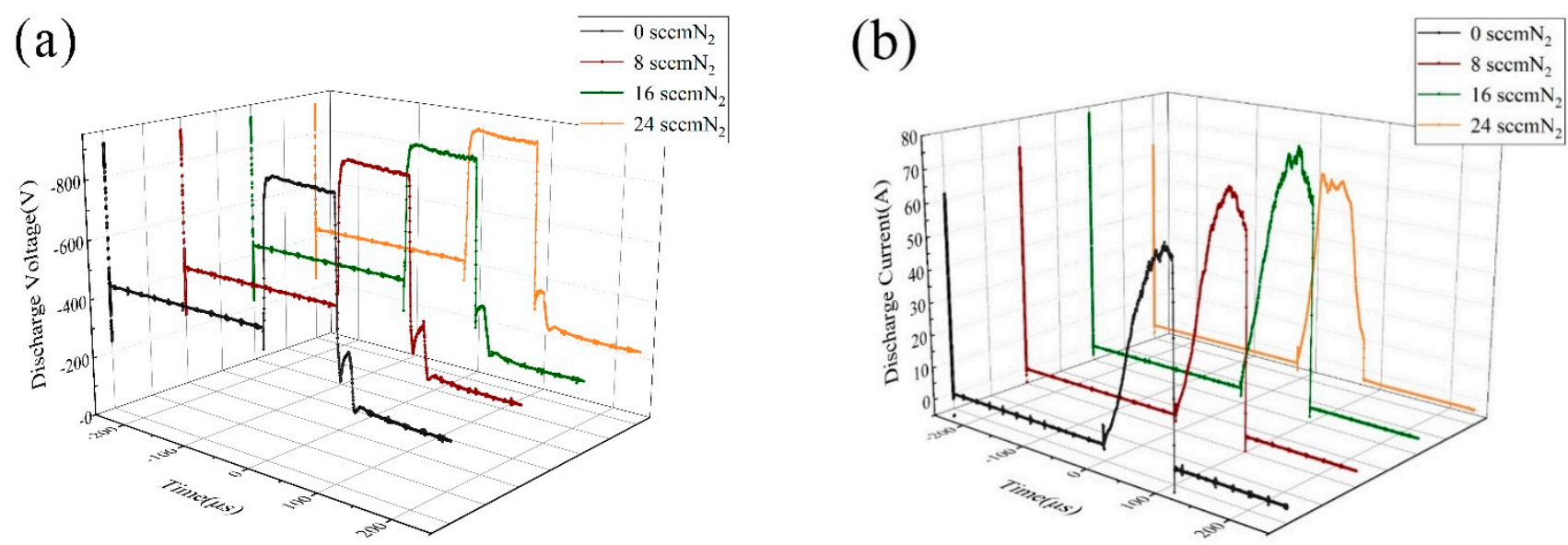

Figure 2. Evolution of the cathode voltage and discharge current with the nitrogen gas flow during the coatings deposition using HiPIMS. (a) Discharge Voltage; (b) Discharge Current.

As a signal representing the species and densities of plasma and the degree of target poisoning in reactive HiPIMS process, the optical emission spectra are collected within set integration time continuously to examine the influence of the addition of nitrogen. The average spectral line intensities calculated over several HiPIMS pulses and their afterglow as a function of the nitrogen gas flow in the range of 200-1000 nm are displayed in Figure 3. The spectral dates of emission lines are presented in Table 2. It is obvious that the addition of nitrogen gas leads to significant changes in plasma characteristic spectrum. With the increase of nitrogen gas flow, the intensities of the emission lines originated from the $\mathrm{W}$ $\mathrm{I}\left(\mathrm{W}^{0}\right)$, N I $\left(\mathrm{N}^{0}\right)$, Ar I $\left(\mathrm{Ar}^{0}\right)$, and $\mathrm{Ar}$ II $\left(\mathrm{Ar}^{+}\right)$first increase and then decrease, the emission intensity of the $\mathrm{CI}\left(\mathrm{C}^{0}\right)$ lines decrease. The emission characteristics changes with increasing nitrogen gas flow could be explained as follows. In magnetron sputtering (HiPIMS), the intensity of emission lines is positive correlation with the number density of emitting atoms, which is determined primarily by electron-driven processes such as electron impact excitation of the atom in its electronic ground state and of an excited metastable level that lies energetically below the emitting level. The formation rate of ionized and excited atoms via electron-driven processes depends essentially on three parameters, the electron temperature $\left(T_{e}\right)$, the electron density at a given electron energy $\left(n_{e}\right)$ and the density of the respective atoms $(N)[20]$. As to W I $\left(\mathrm{W}^{0}\right)$, N I $\left(\mathrm{N}^{0}\right)$, $\mathrm{Ar} \mathrm{I}\left(\mathrm{Ar}^{0}\right)$, and $\mathrm{Ar} \mathrm{II}$, when the 
nitrogen gas flow increases, (i) the number of atoms involved in sputtering increases result in the increasing frequency of collisions between particles, which in turn produce more secondary electrons. These secondary electrons conduced more Ar atoms to ionize. (ii) Some of the ionized nitrogen atoms rush toward and impact the target under the attraction of cathode and lead to more tungsten atoms being sputtered out. So, the intensities of W I $\left(\mathrm{W}^{0}\right), \mathrm{N}$ I $\left(\mathrm{N}^{0}\right)$, Ar I $\left(\mathrm{Ar}^{0}\right)$ and Ar II $\left(\mathrm{Ar}^{+}\right)$emission lines increase. As the nitrogen gas flow further increases, more collisions will occur and lead to a shorter mean free path, which in turn results in lower ions' kinetic energy [15,21]. The insufficient kinetic energy reduces the ionization and excitation rate of particles. Meanwhile, excess reaction gas can lead to target poisoning, which will also reduce the intensity of the elements emission lines [22,23]. As to $\mathrm{C} \mathrm{I}\left(\mathrm{C}^{0}\right)$, the addition of nitrogen gas leads to a reduction in the collision probability and ionization rate of $\mathrm{C}$ atoms, thus reducing the spectral strength.

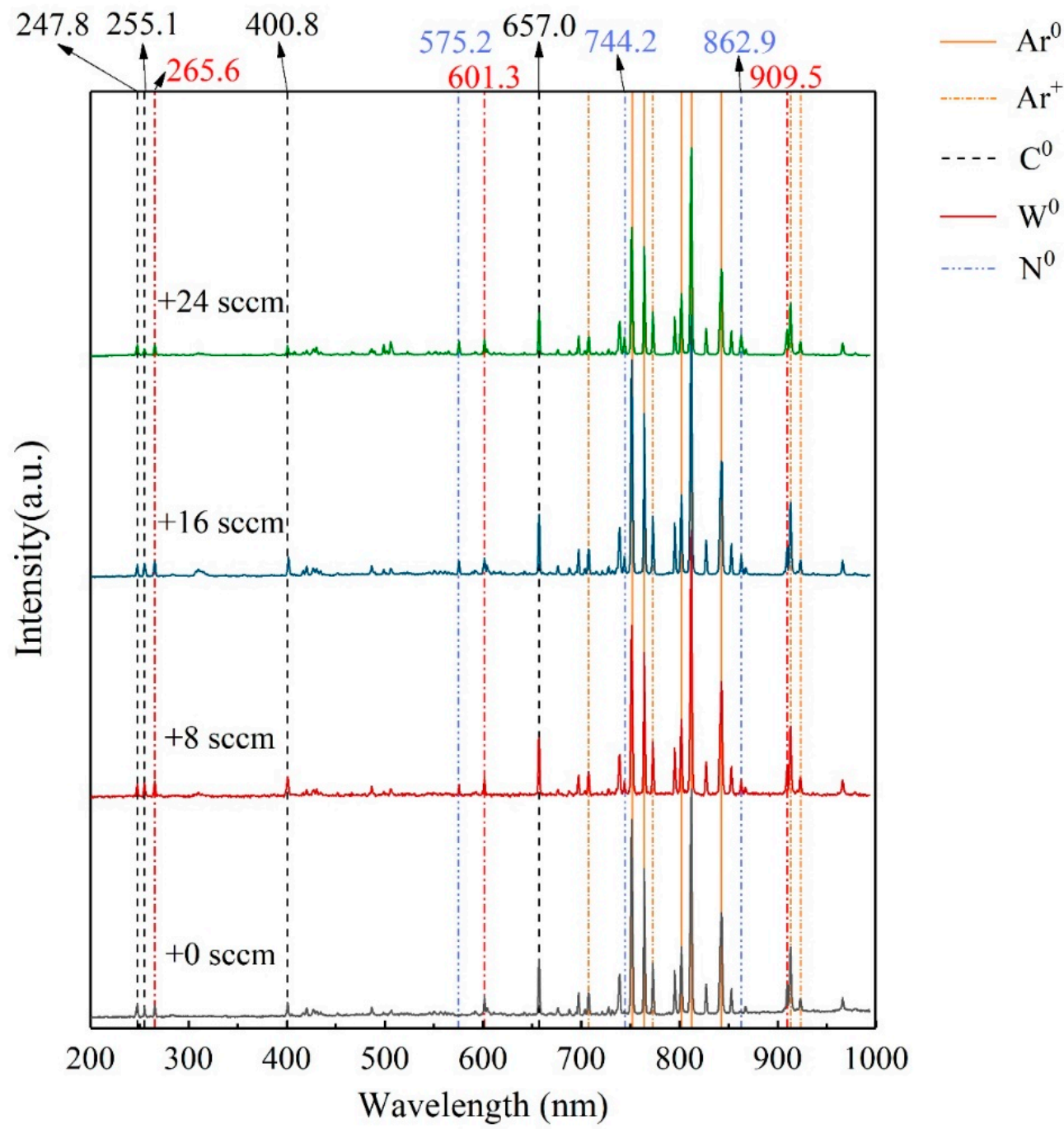

Figure 3. Normalized OES spectrum recorded during HiPIMS with various nitrogen gas flow showing the emission intensities from $\mathrm{W}, \mathrm{C}, \mathrm{N}$ and $\mathrm{Ar}$. 
Table 2. The spectral dates of indicated W,C,N emission lines in Figure 2.

\begin{tabular}{|c|c|c|c|c|c|}
\hline \multirow{3}{*}{ Species } & \multirow{3}{*}{$\begin{array}{l}\text { Position } \\
\text { (nm) }\end{array}$} & \multicolumn{4}{|c|}{ Intensity (Relative, a.u.) } \\
\hline & & \multicolumn{4}{|c|}{ Samples (Different $N_{2}$ Flow Rates) } \\
\hline & & $+0 \mathrm{Sccm}$ & $+8 \mathrm{Sccm}$ & $+16 \mathrm{Sccm}$ & $+24 \mathrm{Sccm}$ \\
\hline \multirow{3}{*}{ W0 } & 265.6 & 524.4 & 703.8 & 675.1 & 515.0 \\
\hline & 601.3 & 963.7 & 921.3 & 832.3 & 783.3 \\
\hline & 909.5 & 1463.9 & 1385.5 & 1298.0 & 1182.1 \\
\hline \multirow{4}{*}{$\mathrm{C} 0$} & 247.8 & 627.9 & 592.3 & 549.9 & 514.1 \\
\hline & 255.1 & 460.8 & 626.8 & 598.1 & 318.4 \\
\hline & 400.8 & 664.1 & 915.7 & 859.5 & 462.6 \\
\hline & 657.0 & 2647.9 & 2682.3 & 2807.5 & 1942.8 \\
\hline \multirow{3}{*}{ No } & 575.2 & 127.0 & 553.5 & 682.6 & 655.9 \\
\hline & 744.2 & 281.5 & 722.5 & 906.2 & 860.6 \\
\hline & 862.9 & 244.2 & 780.2 & 957.8 & 930.2 \\
\hline
\end{tabular}

\subsection{Microstructure and Morphology}

Figure 4 presents the XRD diffractograms of WC coating and WCN coatings using HiPIMS with different addition of nitrogen gas. The WC coating (with $0 \mathrm{sccm} \mathrm{N}_{2}$ ) exhibited the diffraction peaks at $2 \theta \sim 39.57^{\circ}, 53.30^{\circ}$ and $61.85^{\circ}$ corresponding to multiple orientations of (101), (102) and (110) respectively, characteristic of rhombohedral $\beta-W_{2} C$ phase [JCPDS data file card \#35-0776]. With the addition of nitrogen, (101) diffraction peak of the deposited coatings shift to low angle (get closer to (111) diffraction peak of face-centered cubic (fcc) $\beta-W_{2} N$ [JCPDS data file card \#25-1257]), which could be attributed to (111) preferential orientation of face-centered cubic $(\mathrm{fcc}) \beta-\mathrm{W}(\mathrm{CN})$ phase whose positions lie intermediate between those for bulk $\mathrm{W}_{2} \mathrm{C}$ and $\mathrm{W}_{2} \mathrm{~N}$ phases according to other researchers' work [24-26]. Moreover, with the nitrogen flow increasing, the (102) and (110) peaks' intensities and the angle of (101) peak of $\beta-W_{2} C$ phase decrease to disappear, indicating the nitrogen atoms could replace carbon atoms in the lattice of $\beta-\mathrm{W}_{2} \mathrm{C}$ to form $\beta-\mathrm{W}(\mathrm{CN})$ crystallites gradually. Furthermore, no visible peaks of $\mathrm{W}_{2} \mathrm{~N}$ crystalline phase are observed, also suggesting that no pure $\mathrm{W}_{2} \mathrm{~N}$ phase is formed and the added nitrogen atoms are likely incorporated in the FCC lattice of $\mathrm{W}(\mathrm{CN})$ phase [24].

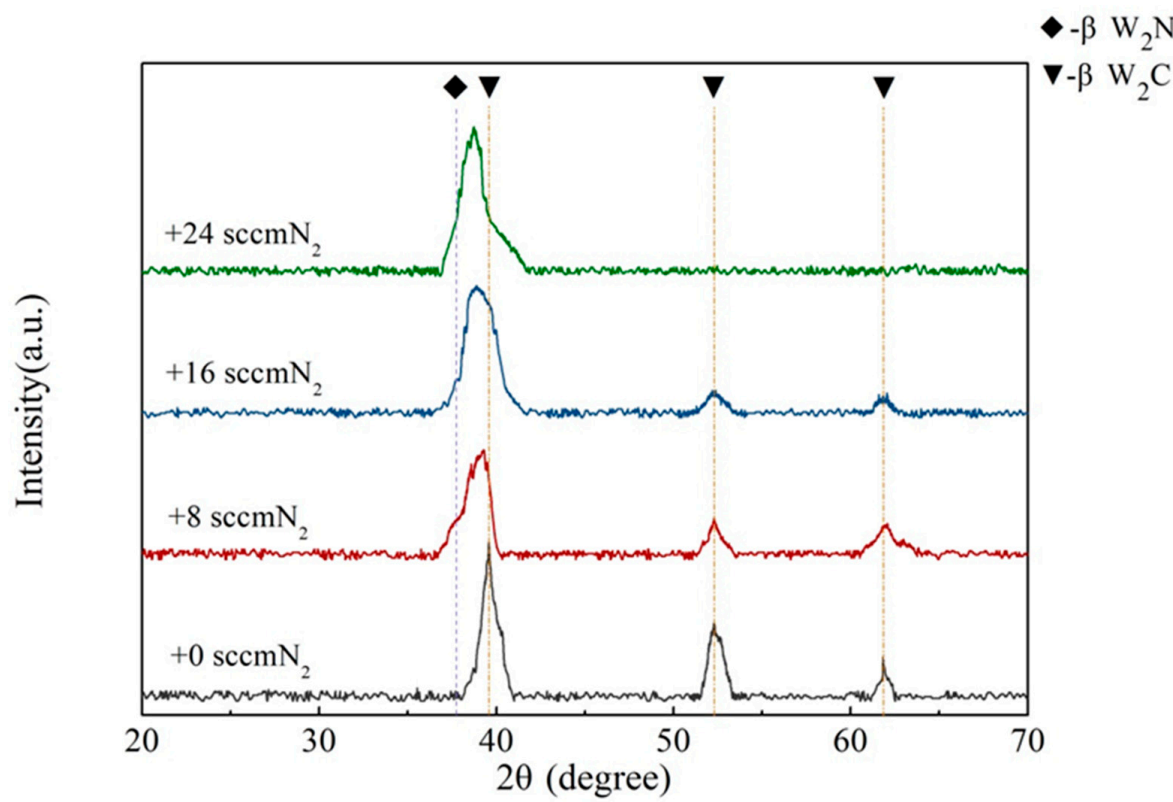

Figure 4. X-ray diffractograms of WC-DLC coatings deposited using HiPIMS with various nitrogen gas flow. 
To analyze the $\mathrm{W}_{2} \mathrm{C}, \mathrm{W}_{2} \mathrm{~N}$ and $\mathrm{W}(\mathrm{CN})$ phases, the average grain size is calculated from the full-width-half-maximum (FWHM) of (101) and (111) diffraction peaks using the Debye-Scherrer equation. The broadening of peaks reflects a decrease of the average grain size from $8.9 \mathrm{~nm}$ to $6.4 \mathrm{~nm}$ with the $\mathrm{N}_{2}$ flow rate increasing from $0 \mathrm{sccm}$ to $24 \mathrm{sccm}$. Reasons for decrease of grain size of the deposited coatings are as follows: (i) With the addition of nitrogen gas, the densities of particles participating in the sputtering and arriving at the substrate becomes higher, which result in random interruptions of the growing grains and then induces more sites promoting secondary nucleation. (ii) The enhanced bombardment density of high-energy gas particles promotes grain boundary migration and leads to point defects that favor nucleation $[27,28]$. (iii) With the increasing addition of nitrogen, the total working pressure increases, which leads to more frequent collisions and lower kinetic energy carried by the bombarding ions may also be a reason for grain refinement [29].

In order to acquire further information about crystalline phases and bonds structure of the deposited coatings, high-resolution XPS spectra of C 1s, N 1s and W $4 \mathrm{f}$ were deconvoluted, respectively. C 1s peak at $284.6 \mathrm{eV}$ was used as a reference to calibrated the spectra $[30,31]$. Figure 5 shows the XPS core-level spectra, in which Figure $5 \mathrm{a} 1, \mathrm{~b} 1, \mathrm{c} 1$ are overall spectra and Figure $5 \mathrm{a} 2-\mathrm{a} 5, \mathrm{~b} 2-\mathrm{b} 5, \mathrm{c} 2-\mathrm{c} 5$ are detail spectra in the energy region of $\mathrm{C} 1 \mathrm{~s}, \mathrm{~N} 1 \mathrm{~s}$ and $\mathrm{W} 4 \mathrm{f}$ for the deposited coatings with different nitrogen flow rates. As shown in Figure 5a2, the fitted C 1s spectrum centered at $283.5 \pm 0.1 \mathrm{eV}, 284.5 \pm 0.1 \mathrm{eV}$ and $286.5 \pm 0.1 \mathrm{eV}$ are recognized as $\mathrm{C}-\mathrm{W}, \mathrm{C}-\mathrm{C}(: \mathrm{H})$ and $\mathrm{C}-\mathrm{O}[26,32-34]$. The presence of free oxygen might from residual oxygen in the vacuum chamber during the coatings ${ }^{\prime}$ deposition. After the nitrogen pumped in, there is a new fitted peak located at around $286.1 \pm 0.1 \mathrm{eV}$ emerged in the $\mathrm{C} 1 \mathrm{~s}$ spectra (Figure 5a3-a5), which is identified as $\mathrm{C}=\mathrm{N}$ bonds [26]. And with the increasing of nitrogen flow rate, the intensity of $\mathrm{C}=\mathrm{N}$ peak increases while the intensity of $\mathrm{C}-\mathrm{W}$ peak decreases. The variation tendency of carbon bondings is in good agreement with the studies of other researchers [32,35].

In the N 1s XPS spectra (Figure 5b1-b5), the pure WC coating (Figure 5b2) shows no useful information. As is shown in Figure $5 \mathrm{~b} 1$, when the $\mathrm{N}_{2}$ flow rate increased from $8 \mathrm{sccm}$ to $24 \mathrm{sccm}$, the peak intensity of $\mathrm{N} 1 \mathrm{~s}$ increased, which was in accordance with the increase of $\mathrm{N}$ content in the deposited coatings. And the $\mathrm{N} 1 \mathrm{~s}$ spectra in Figure $5 \mathrm{~b} 3-\mathrm{b} 5$ show four peaks at $396.9 \pm 0.1 \mathrm{eV}, 398.1 \pm 0.1 \mathrm{eV}, 399 \pm 0.1 \mathrm{eV}$ and $400.8 \pm 0.1 \mathrm{eV}$, representing $\mathrm{WN}$, $\mathrm{W}-\mathrm{C}-\mathrm{N}, \mathrm{C}=\mathrm{N}$ and $\mathrm{N}-\mathrm{O}$, respectively $[25,26,36,37]$. It is worth noting that the ratio of peak intensity of $\mathrm{W}-\mathrm{N}$ to $\mathrm{W}-\mathrm{C}-\mathrm{N}$ and $\mathrm{C}=\mathrm{N}$ increases with the increasing $\mathrm{N}_{2}$ flow rate, meaning that more $\mathrm{W}-\mathrm{N}$ bonds are formed in WCN coatings at higher $\mathrm{N}$ concentration.

Figure $5 \mathrm{c} 1-\mathrm{c} 5$ presents the fitted $\mathrm{W} 4 \mathrm{f}$ spectra, it could be seen that $\mathrm{W} 4 \mathrm{f}$ spectra exhibits two components: $\mathrm{W} 4 \mathrm{f}_{7 / 2}$ and $\mathrm{W} 4 \mathrm{f}_{5 / 2}$ and each component has a doublet structure composed of a high-energy main peak and a low-energy satellite peak. The $\mathrm{W} 4 \mathrm{f}_{7 / 2}$ peak located at $31.7 \pm 0.2 \mathrm{eV}$ between the binding energies of $\mathrm{W}-\mathrm{C}(31.3 \pm 0.1 \mathrm{eV})$ and $\mathrm{W}-\mathrm{N}$ $(33.1 \pm 0.1 \mathrm{eV})$ is considered as the formation of $\mathrm{W}-\mathrm{C}-\mathrm{N}$ bonds $[25,26]$. The $\mathrm{W} 4 \mathrm{f}_{5 / 2}$ peak at $33.8 \pm 0.2 \mathrm{eV}$ is also attributed to $\mathrm{W}-\mathrm{C}-\mathrm{N}$ bonds as reported by R. Ospina [26] and J.F. Moulder [38]. And the appearing peaks at the high binding energies of $35.6 \pm 0.2 \mathrm{eV}$ and $37.6 \pm 0.1 \mathrm{eV}$ are corresponding to $\mathrm{W}-\mathrm{O}\left(4 \mathrm{f}_{7 / 2}\right)$ and $\mathrm{W}-\mathrm{O}\left(4 \mathrm{f}_{5 / 2}\right)$, respectively [39]. According to the fitted $\mathrm{W} 4 \mathrm{f}$ spectra, it can be seen $\mathrm{W}-\mathrm{C}-\mathrm{N}$ bonds slightly shift to higher binding energy, which also could be attributed to the formation of W-N bonds with the increase of nitrogen flow rate.

Figure 6 displays the cross-sectional SEM micrographs of WC/WCN composite coatings deposited with different $\mathrm{N}_{2}$ flow rates. It is can be seen with the increase of nitrogen flow rate, the cross-sectional morphologies of deposited coatings change from slight columnar type to a typical dense and featureless structure. Further, as the $\mathrm{N}_{2}$ flow rate increases, the coatings' thickness increases from $2.64 \mu \mathrm{m}$ at $0 \mathrm{sccm}$ to $3.32 \mu \mathrm{m}$ at $16 \mathrm{sccm}$, then decreases to $2.70 \mu \mathrm{m}$ at $24 \mathrm{sccm}$ corresponding to the deposition rate which increases from $88.0 \mathrm{~nm} / \mathrm{min}$ to $110.7 \mathrm{~nm} / \mathrm{min}$ and then drops to $90.0 \mathrm{~nm} / \mathrm{min}$. The deposition rate, chemical compositions, grain size and surface roughness of WC/WCN coatings with different $\mathrm{N}_{2}$ flow rate are shown in Table 3. This change might be explained as follows: (i) When 
the $\mathrm{N}_{2}$ flow introduced in the deposition is low, with the increase of the addition of $\mathrm{N}_{2}$, the peak discharge current and the deposition power (see in Figure 2) increases, which not only increased the deposition rate, but also led to enhanced fraction of ionized species reaching the growing coating, promoting the mobility of the adatoms and the migration of particles to the grain boundaries and the interruption of columnar structure, consequently, raising a spontaneous compact morphology. (ii) The getter effect in the reactive sputtering: the deposited coatings absorb the reactive gas and the deposition rate increases [40,41]. (iii) When the $\mathrm{N}_{2}$ flow rate increased further, excessive reactive gas leads to target poisoning, which reduces the sputtering of the targets and the peak discharge current. Therefore, the deposition rate decreased with the increased $\mathrm{N}_{2}$ flow rate.
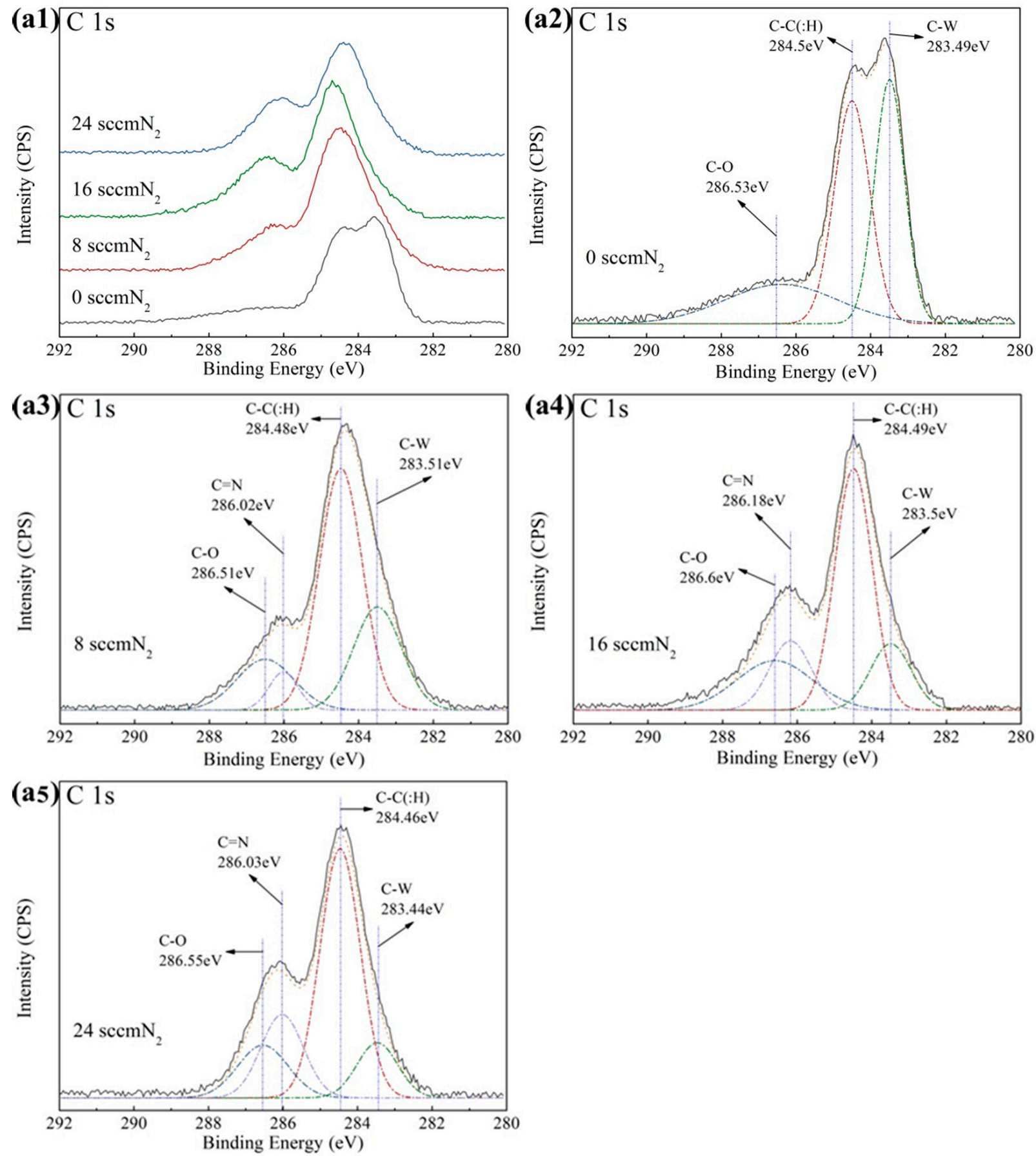

Figure 5. Cont. 

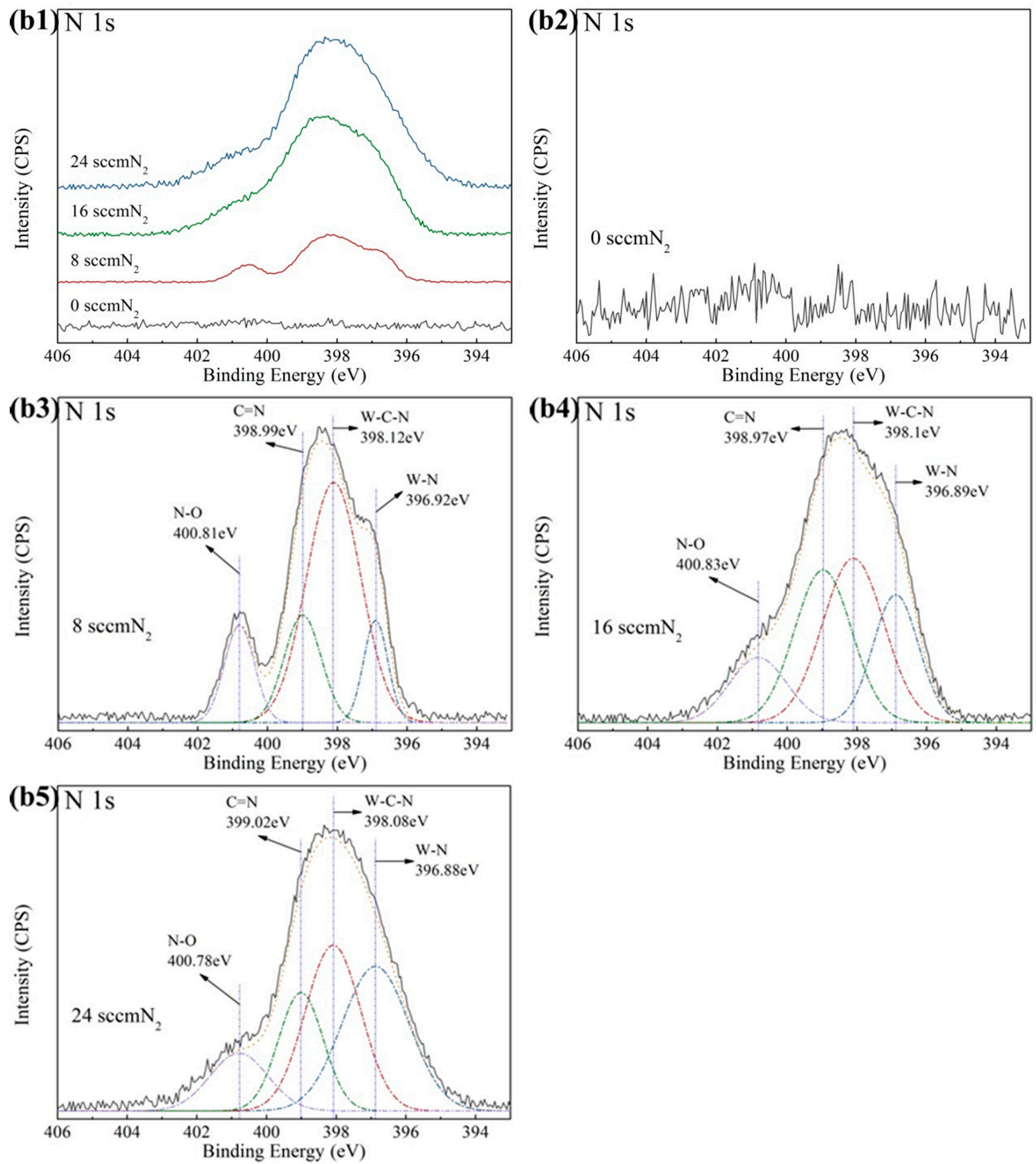

Figure 5. Cont. 

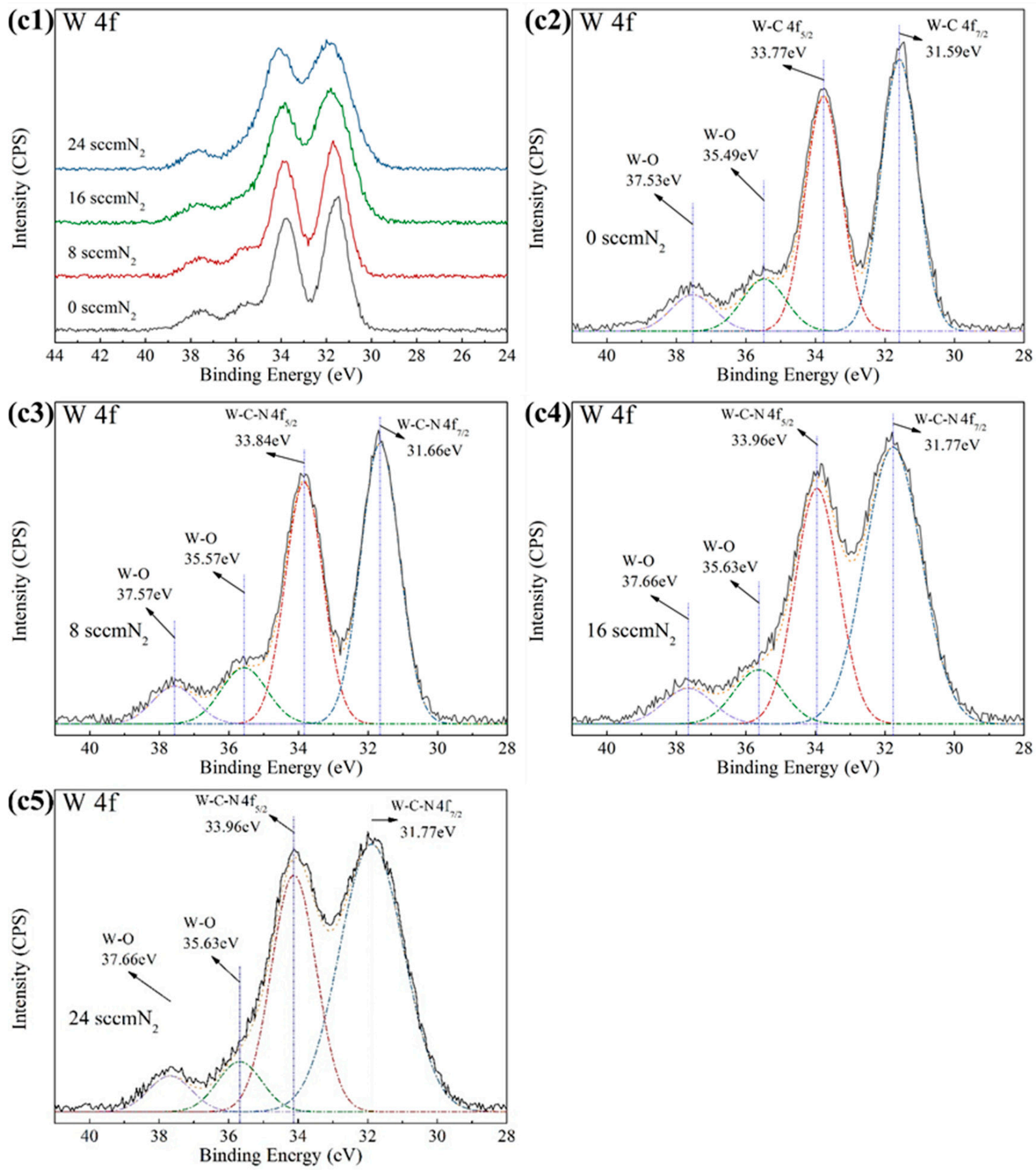

Figure 5. C 1s, N 1s and W 4f core level XPS spectra of WC/WCN coatings deposited at different nitrogen flow rates. ((a):C 1s; (b): N 1s; (c): W 4f) of overall (a1,b1,c1), +0 sccm N $2(\mathbf{a} 2, \mathbf{b} 2, \mathrm{c} 2),+8 \mathrm{sccm} \mathrm{N} 2(\mathbf{a} 3, \mathbf{b} 3, \mathrm{c} 3),+16 \mathrm{sccm} \mathrm{N} \mathrm{N}_{2}(\mathbf{a} 4, \mathbf{b} 4, \mathbf{c} 4)$ and +24 sccm $\mathrm{N}_{2}(\mathbf{a} 5, \mathrm{~b} 5, \mathrm{c} 5)$. 

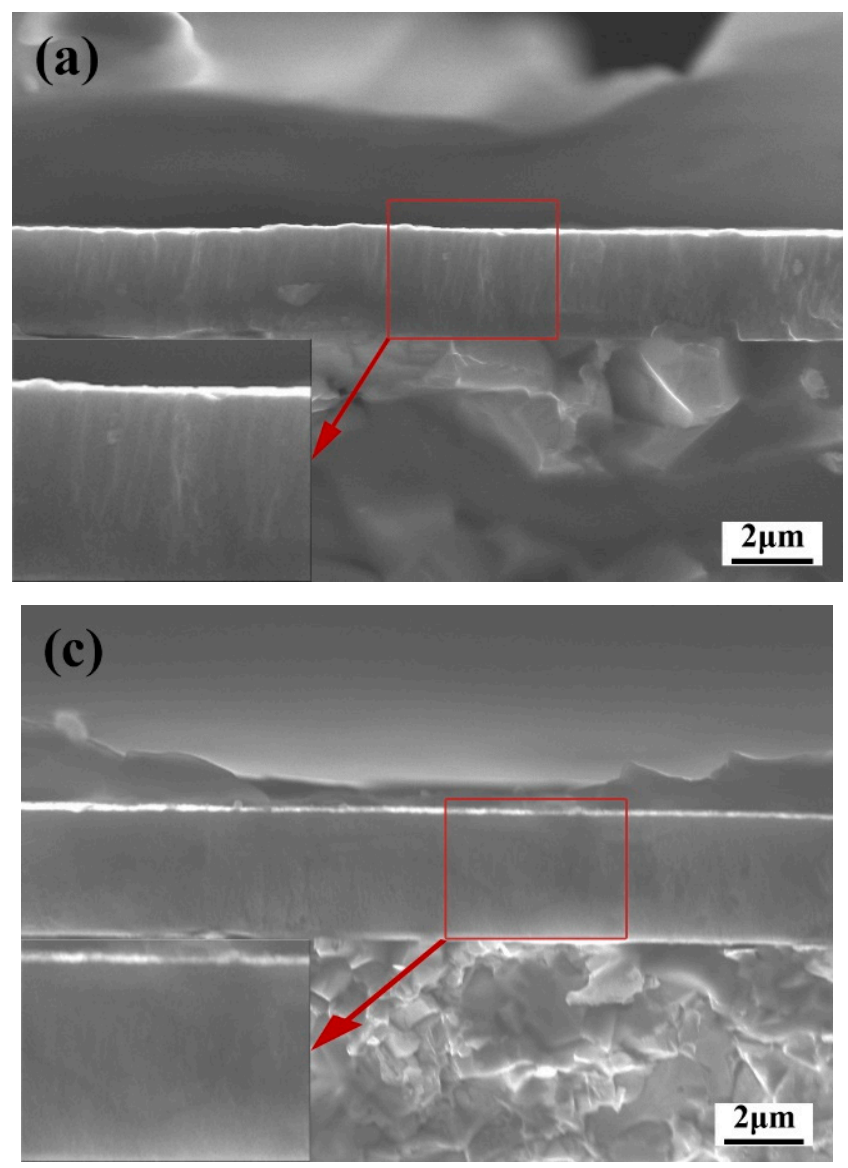

Figure 6. Cross-sectional SEM micrographs of WC/WCN composite coatings with different nitrogen flow rates. (a) +0 sccm $\mathrm{N}_{2},(\mathbf{b})+8 \mathrm{sccm} \mathrm{N}_{2},(\mathbf{c})+16 \mathrm{sccm} \mathrm{N}_{2},(\mathbf{d})+24 \mathrm{sccm} \mathrm{N} \mathrm{N}_{2}$.

Table 3. The deposition rate, grain size and roughness of $\mathrm{WC} / \mathrm{WCN}$ coatings with different $\mathrm{N}_{2}$ flow rate.

\begin{tabular}{|c|c|c|c|c|c|c|}
\hline \multirow{2}{*}{ Samples } & \multirow{2}{*}{$\begin{array}{c}\text { Deposition } \\
\text { Rate (nm/min) }\end{array}$} & \multirow{2}{*}{$\begin{array}{l}\text { Grain Size } \\
\quad(\mathrm{nm})\end{array}$} & \multirow{2}{*}{$\begin{array}{l}\text { Roughness } \\
\text { (Ra/nm) }\end{array}$} & \multicolumn{3}{|c|}{ Chemical Compositions } \\
\hline & & & & $\mathbf{W}$ & $\mathrm{C}$ & $\mathbf{N}$ \\
\hline Sample1 (0 sccm) & 88.0 & 8.9 & 11.6 & $67.8 \pm 0.5$ & $32.2 \pm 0.3$ & - \\
\hline Sample2 (8 sccm) & 96.4 & 7.7 & 9.5 & $62.9 \pm 0.7$ & $32.0 \pm 0.2$ & $5.1 \pm 0.2$ \\
\hline Sample3 (16 sccm) & 110.7 & 6.8 & 8.2 & $57.4 \pm 0.8$ & $30.2 \pm 0.4$ & $12.4 \pm 0.4$ \\
\hline Sample4 (24 sccm) & 90.0 & 6.4 & 5.7 & $51.6 \pm 0.6$ & $29.2 \pm 0.4$ & $19.2 \pm 0.3$ \\
\hline
\end{tabular}

As is shown in Table 3, with the increasing input nitrogen gas, the $\mathrm{N}$ content increased from $0 \%$ to 19.2 at.\%. And the composition of $\mathrm{W} / \mathrm{C}$ ratio in the deposited coatings was below 2.33 (7:3) which is the ratio of the target and decreased with the increasing $\mathrm{N}_{2}$ flow rate. This phenomenon is attributed to target poisoning and preventing the escape of metal $\mathrm{W}$ atoms from WC target surface.

In order to see the variation of surface morphology and surface roughness with the $\mathrm{N}_{2}$ flow rate, the three-dimensional topographic AFM images of WC/WCN coatings deposited onto silicon (100) wafers with different nitrogen gas flow are compared in Figure 7. It is obvious that all coatings have a granular structure with visible, agglomerated grains and the grain size decreases with the increase of the nitrogen gas flow, indicating a smoothing trend of the coatings' surface. The surface roughness of the coatings decreases from Ra $11.6 \mathrm{~nm}$ at $0 \mathrm{sccm}$ to Ra $5.7 \mathrm{~nm}$ at $24 \mathrm{sccm}$. The decreases of surface roughness can be attributed to the addition of $\mathrm{N}$ to $\mathrm{W}_{2} \mathrm{C}$ and promotes the continuous nucleation process leading to the grain refinement, which is in agreement with the variation tendency of grain size. 
(a)

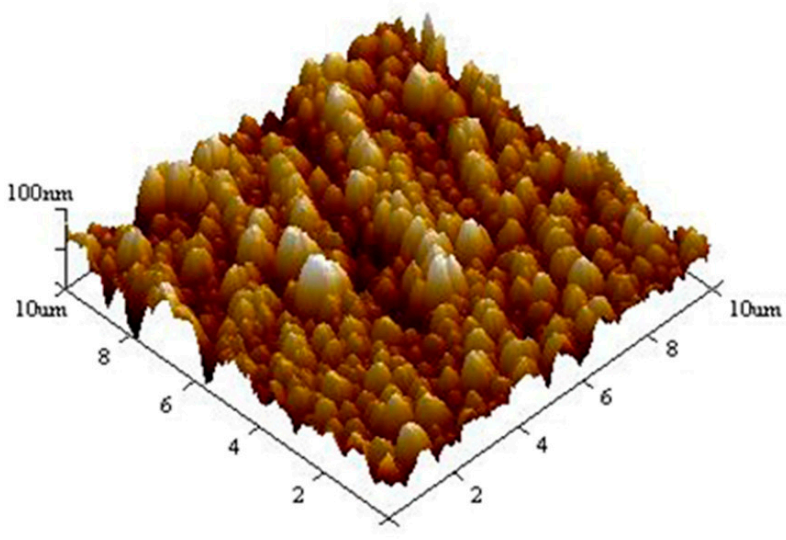

Ra 11.6nm

(c)

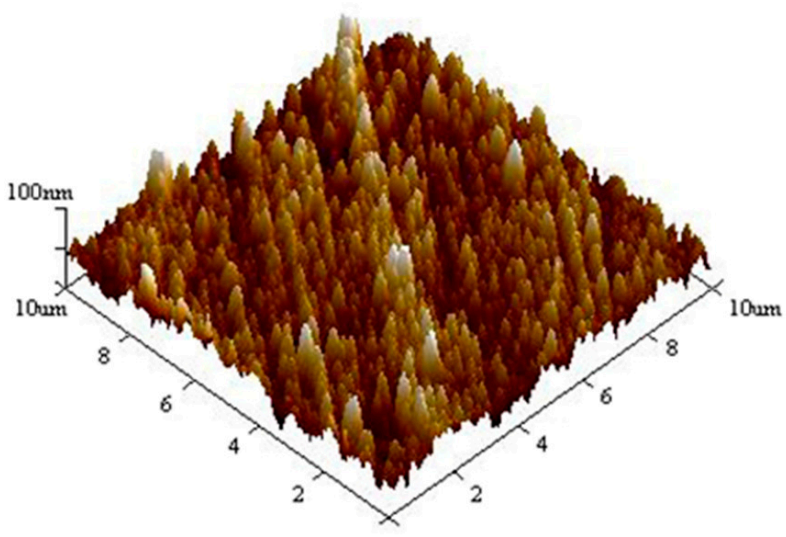

Ra $8.2 \mathrm{~nm}$

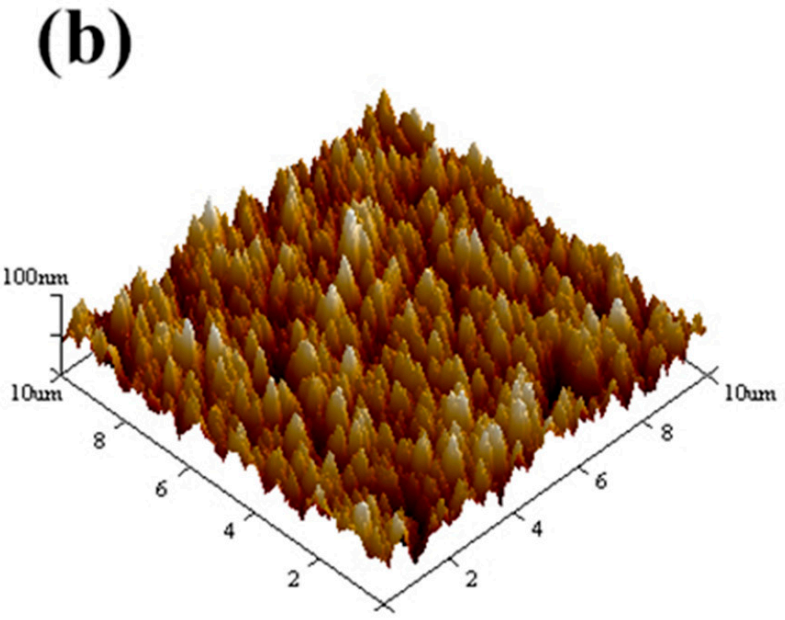

Ra 9.5nm

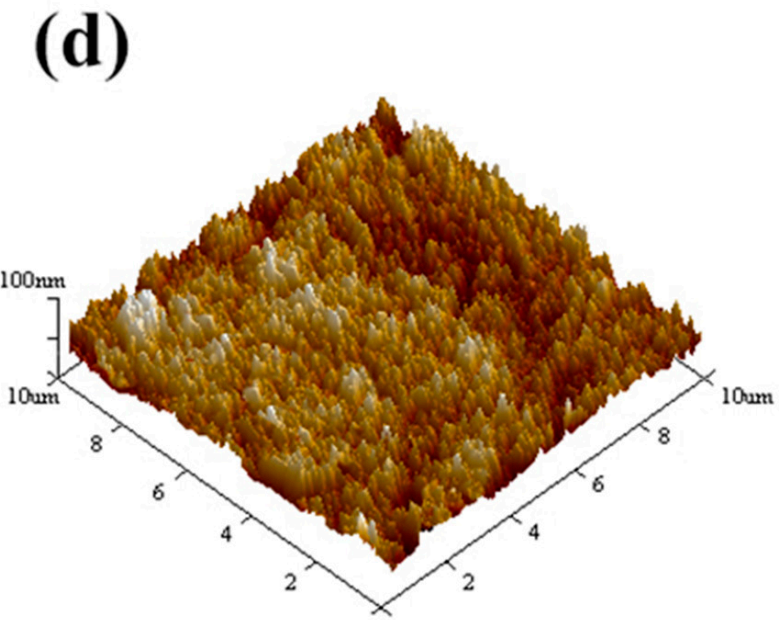

Ra $5.7 \mathrm{~nm}$

Figure 7. $\mathrm{AFM}$ images of $10 \times 10 \mu \mathrm{m}^{2}$ scan area of $\mathrm{WC} / \mathrm{WCN}$ coatings prepared with various nitrogen flow rates. (a) $+0 \mathrm{sccm} \mathrm{N} \mathrm{N}_{2}$, (b) $+8 \mathrm{sccm} \mathrm{N}_{2}$, (c) $+16 \mathrm{sccm} \mathrm{N}_{2}$, (d) $+24 \mathrm{sccm} \mathrm{N} \mathrm{N}_{2}$.

\subsection{Mechanical and Tribological Properties}

Figure 8 displays the hardness $(\mathrm{H})$ and elastic modulus (E) of WC/WCN coatings deposited with different $\mathrm{N}_{2}$ flow rate. As is shown, the hardness and elastic modulus first increases then decreases with the increase of $\mathrm{N}_{2}$ flow rate, and peaked at $35.6 \mathrm{GPa}$ and $476.5 \mathrm{GPa}$ at $16 \mathrm{sccm}$, respectively. The variation of hardness is mainly attributed to the effect of solid solution strengthening and the grain refinement caused by the incorporation of nitrogen atoms [24,25]. Further increasing the $\mathrm{N}_{2}$ flow rate to $24 \mathrm{sccm}$, the hardness and elastic modulus decrease to $33.5 \mathrm{GPa}$ and $450.4 \mathrm{GPa}$, respectively, mainly due to the increase in the content of amorphous CNx according to the result of XPS. 


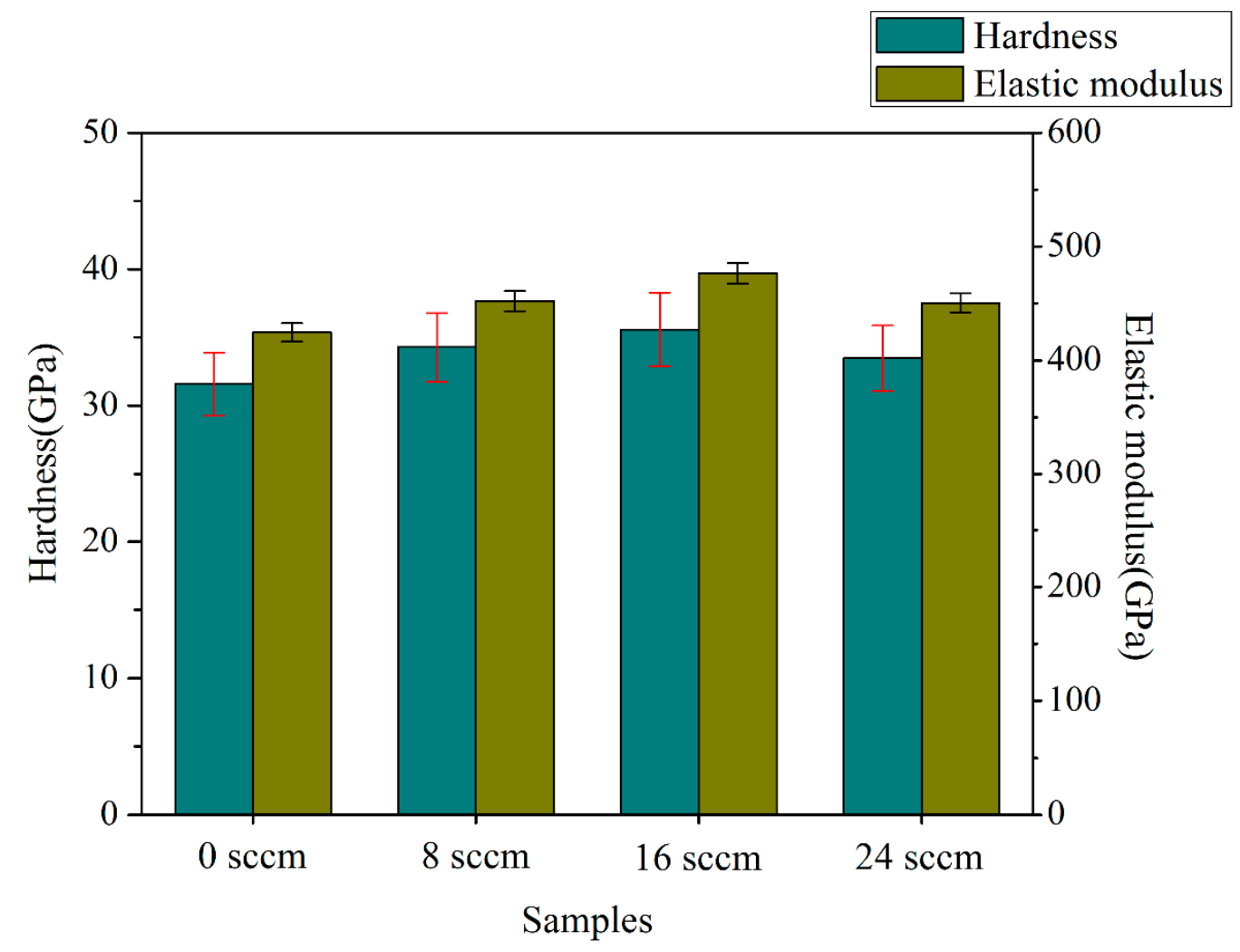

Figure 8. Hardness and Elastic modulus of WC-DLC coatings deposited with different nitrogen gas flow.

The coefficients of friction (COF) of WC/WCN coatings deposited with different $\mathrm{N}_{2}$ flow rate as a function of reciprocating sliding time under dry contact at the room temperature $\left(25^{\circ} \mathrm{C}\right.$, Figure $\left.9 \mathrm{a}\right)$ and elevated temperature $\left(400^{\circ} \mathrm{C}\right.$, Figure $\left.9 \mathrm{~b}\right)$ are exhibited in Figure 9. As is shown in Figure 9a, the values of friction coefficient at RT become stable at approximately $0.12,0.15,0.18$, and 0.23 after a rapid decrease in the initial runningin phase. As reported [42], the high friction coefficient of running-in period is mainly related to the defects on the coating surface and high abrasive forces acting at the sliding interface. Higher nitrogen fluxes lead to higher and less stable friction coefficients in the steady-state. It is clear that the addition of nitrogen affects friction coefficients. All the coatings are not thoroughly worn out in the end of the wear test since the friction coefficients remain approximately constant. Moreover, it is worth noting that the friction coefficient of the coating deposited at $24 \mathrm{sccm}$ fluctuates greater, which indicates the coating partial failure. The friction curves at $400{ }^{\circ} \mathrm{C}$ are illustrated in Figure $9 \mathrm{~b}$. Different from the room temperature wear test, the friction coefficients increase after running-in stage and the friction coefficients of the coatings at $400{ }^{\circ} \mathrm{C}$ are much higher than those at $25^{\circ} \mathrm{C}$, which all could be attribute to the oxidization of coatings at high temperature. The friction curves of the coatings deposited at $0 \mathrm{sccm}$ and $8 \mathrm{sccm}$ increased to approximately 0.6 with large fluctuations after $1900 \mathrm{~s}$ and $3200 \mathrm{~s}$, respectively. When increasing the $\mathrm{N}_{2}$ flow rate to $16 \mathrm{sccm}$, the friction coefficient of the coating remains stable over the entire test range. With a further increase of $\mathrm{N}_{2}$ flow rate, the coating deposited at $24 \mathrm{sccm}$ exhibited a slight fluctuation at the end of the wear test, which indicates the high-temperature tribological properties deteriorate. 
(a)

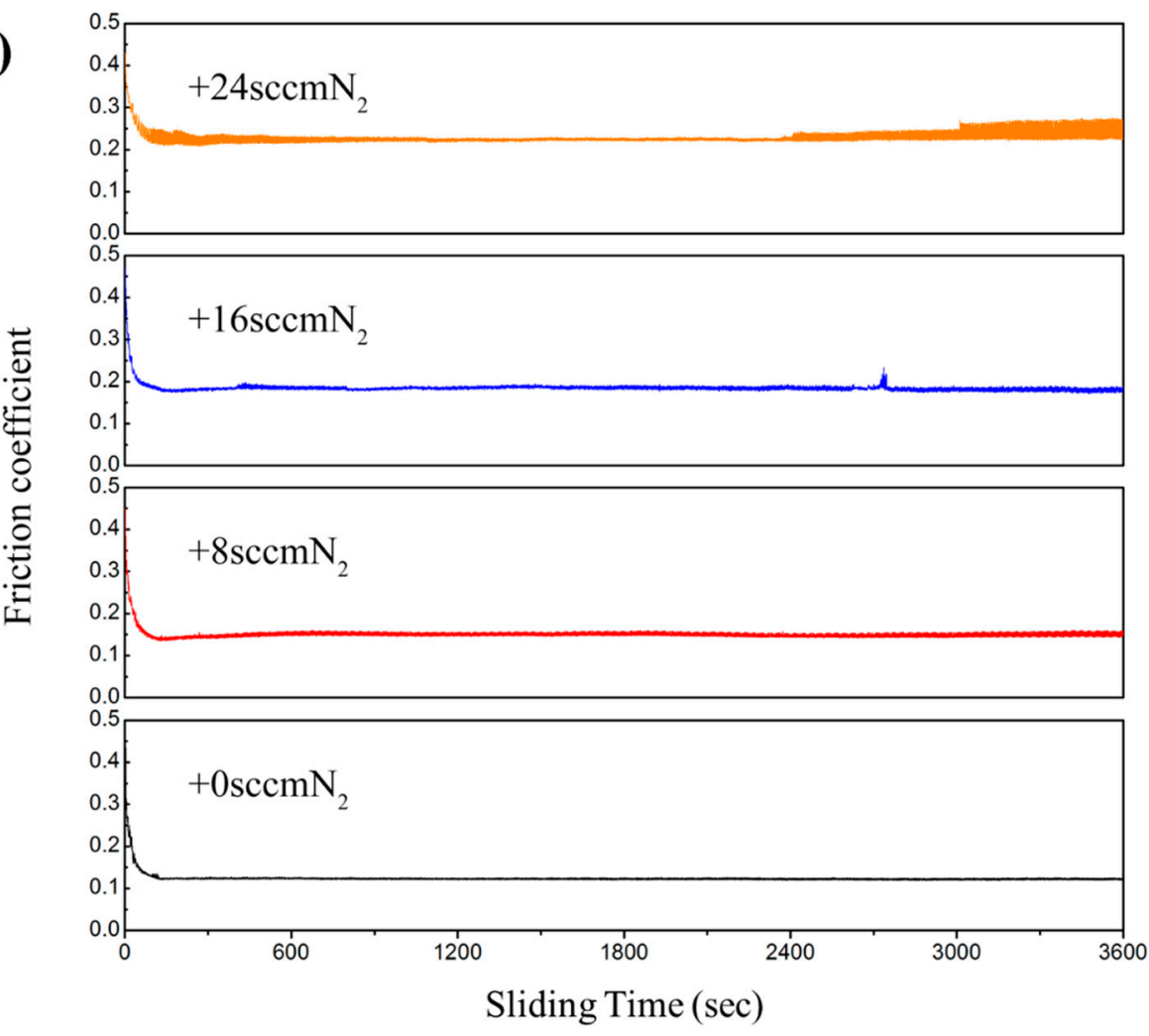

(b)
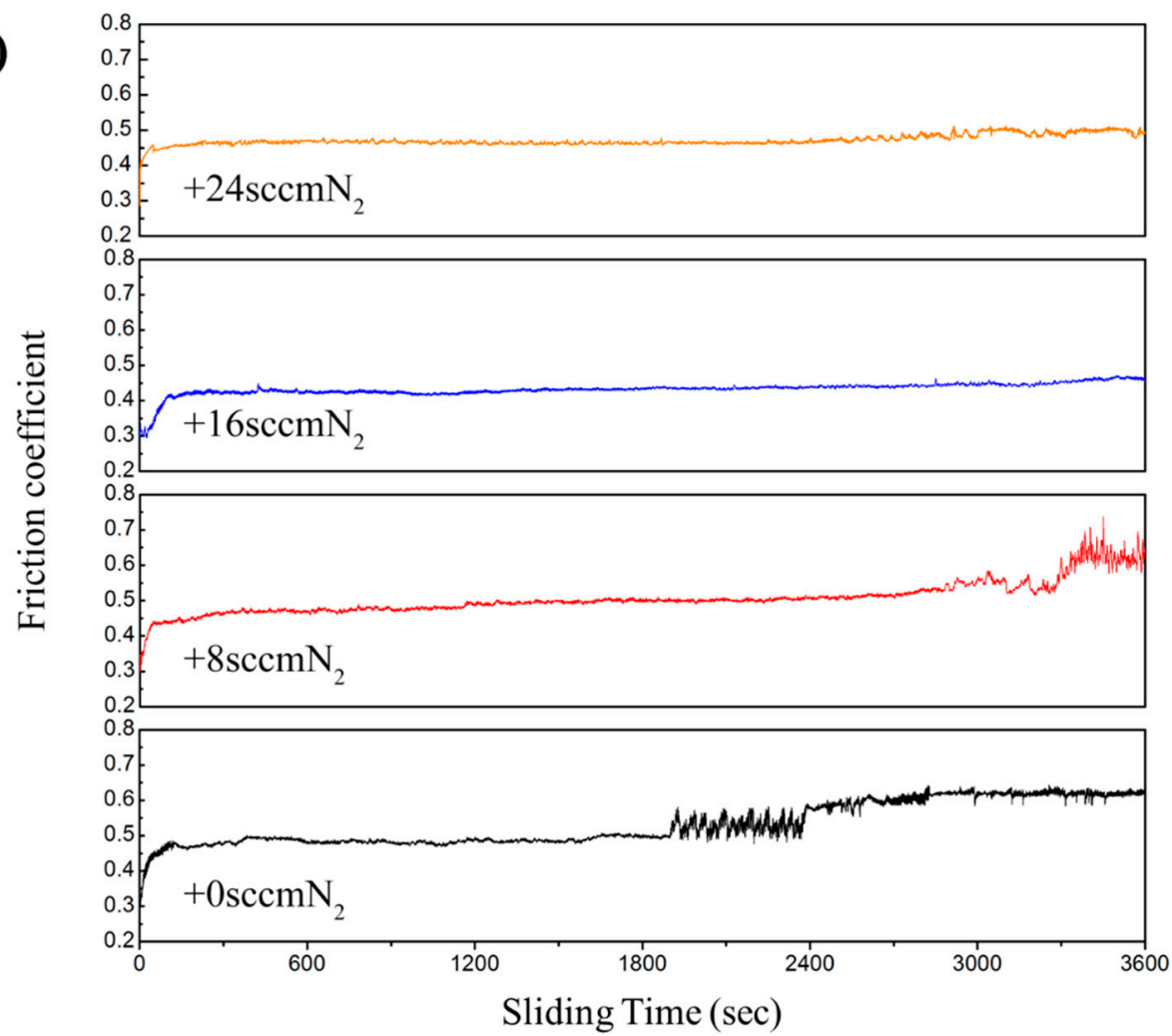

Figure 9. Friction coefficients of WC/WCN coatings deposited with different nitrogen gas flow: (a) $25^{\circ} \mathrm{C},(\mathbf{b}) 400^{\circ} \mathrm{C}$.

In order to further investigate the friction behaviors of the WC/WCN coatings, the SEM images and EDS analysis obtained by field emission scanning electron microscopy 
(FESEM) of wear tracks are presented in Figure 10. At $25^{\circ} \mathrm{C}$ (Figure 10a1-d1), the wear tracks exhibit a tendency to broaden, and the exposed substrate area on wear tracks has been getting larger, which indicates that the room temperature $\left(25^{\circ} \mathrm{C}\right)$ tribological properties of the coatings deteriorates with the increase of the $\mathrm{N}_{2}$ flow rate. The results of EDS analysis demonstrate the Cobalt content in the center of the wear tracks increases with the increase of the $\mathrm{N}_{2}$ flow rate, this also confirm the exposure of the substrate. In particular, the appearance of aluminum element on the wear tracks is due to the transfer of the materials of the counterpart $\mathrm{Al}_{2} \mathrm{O}_{3}$ ball. At $400{ }^{\circ} \mathrm{C}$ (Figure $10 \mathrm{a} 2-\mathrm{d} 2$ ), the width of wear tracks is much wider than that at $25{ }^{\circ} \mathrm{C}$. For the pure WC coating, the wear track is wide with substrate completely exposure. When added $8 \mathrm{sccm} \mathrm{N}_{2}$, the amount of residual coating increased slightly. With the $\mathrm{N}_{2}$ flow rate increases to $16 \mathrm{sccm}$, the width of the wear track gets narrow and remaining coating on the wear track increased significantly. As the nitrogen gas flow further increases to $24 \mathrm{sccm}$, the wear track becomes wider and the amount of residual coating decreases, indicating the high temperature $\left(400{ }^{\circ} \mathrm{C}\right)$ tribological properties deteriorates with excess nitrogen gas supply. It can be clearly seen from the EDS results that the Cobalt content in the center of the wear tracks first decreases then increases with the rise of $\mathrm{N}_{2}$ flow rate, which also demonstrates the variation trends of the high temperature tribological properties of the coatings.
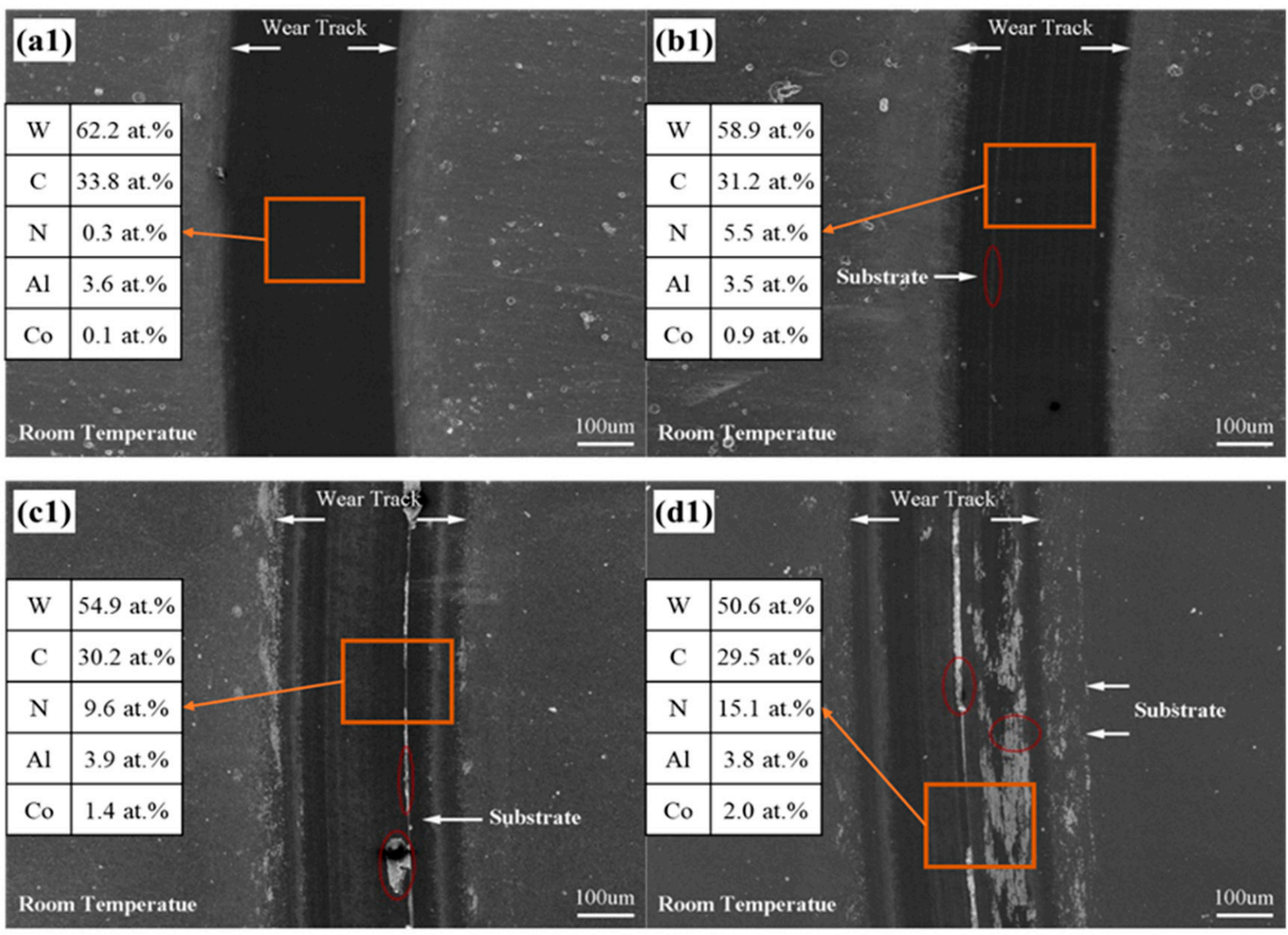

Figure 10. Cont. 

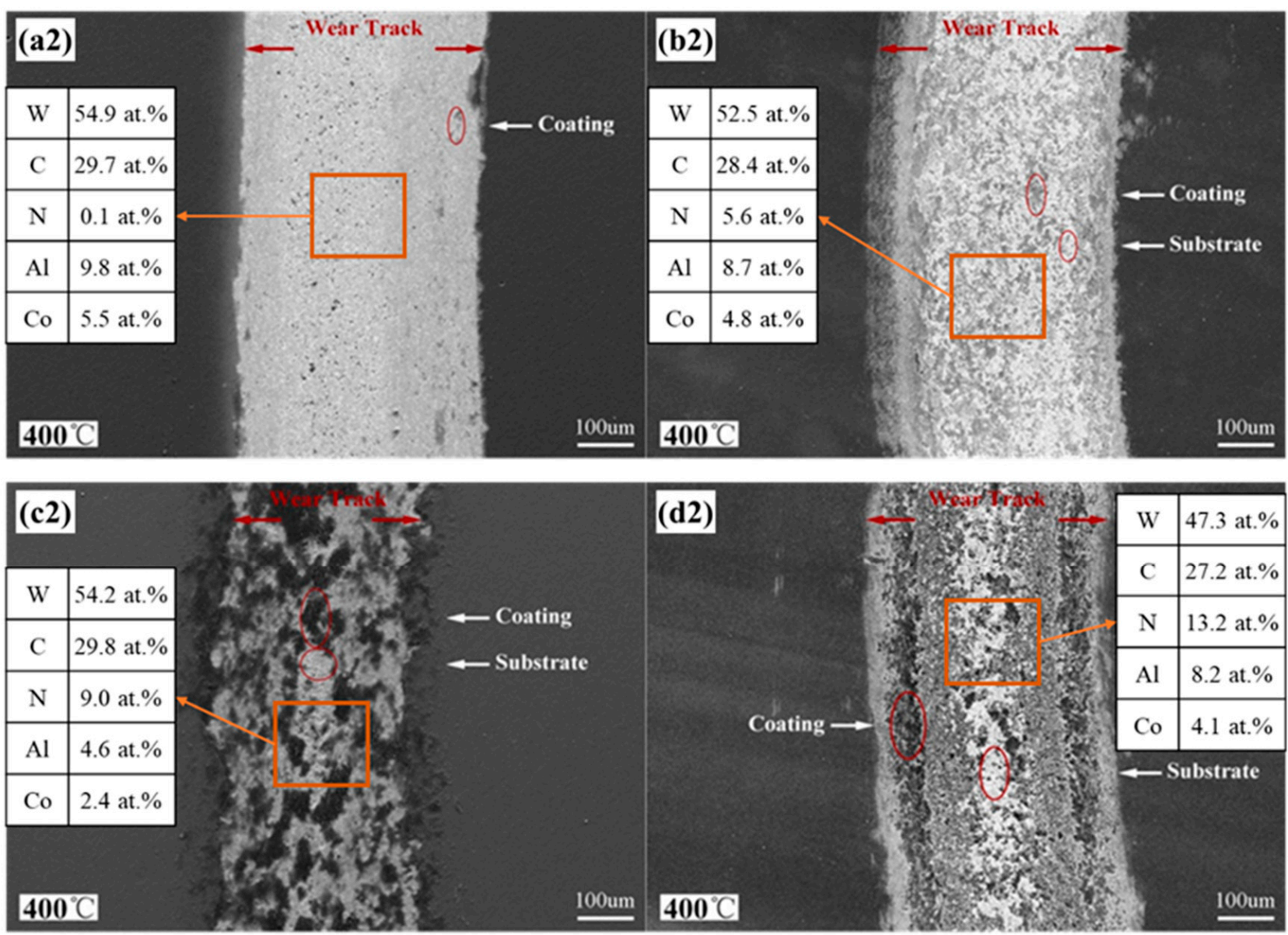

Figure 10. SEM images and EDS analysis of the wear tracks produced by a ball on disk test of WC/WCN coatings deposited with different nitrogen gas flow ((a): $0 \mathrm{sccm}$; (b): $8 \mathrm{sccm}$; (c): $16 \mathrm{sccm} ;(\mathbf{d}): 24 \mathrm{sccm})$ at $25^{\circ} \mathrm{C}(\mathbf{a} 1, \mathbf{d 1})$ and $400{ }^{\circ} \mathrm{C}(\mathbf{a 2}, \mathbf{d 2})$.

The 3D graphs of the wear tracks of WC/WCN coatings deposited with different nitrogen gas flow observed by LCMS are shown in Figure 11. As is shown in Figure 11a2-d2, coatings subjected to wear tests at elevated temperature $\left(400^{\circ} \mathrm{C}\right)$ have much wider and deeper wear tracks compared with those (Figure 11a1-d1) at room temperature $\left(25^{\circ} \mathrm{C}\right)$. This is probably attributed to the oxidation and the increased friction coefficients (see in Figure 9) of the WC/WCN coatings at high temperature. The wear rates of room temperature wear test increase with the increases of nitrogen flow rate, while the wear rates first decrease then increase with the increases of nitrogen flow rate, which are also confirmed by the wear rates of the deposited coatings calculated from the cross-sectional profiles of wear tracks shown in Figure 12. 

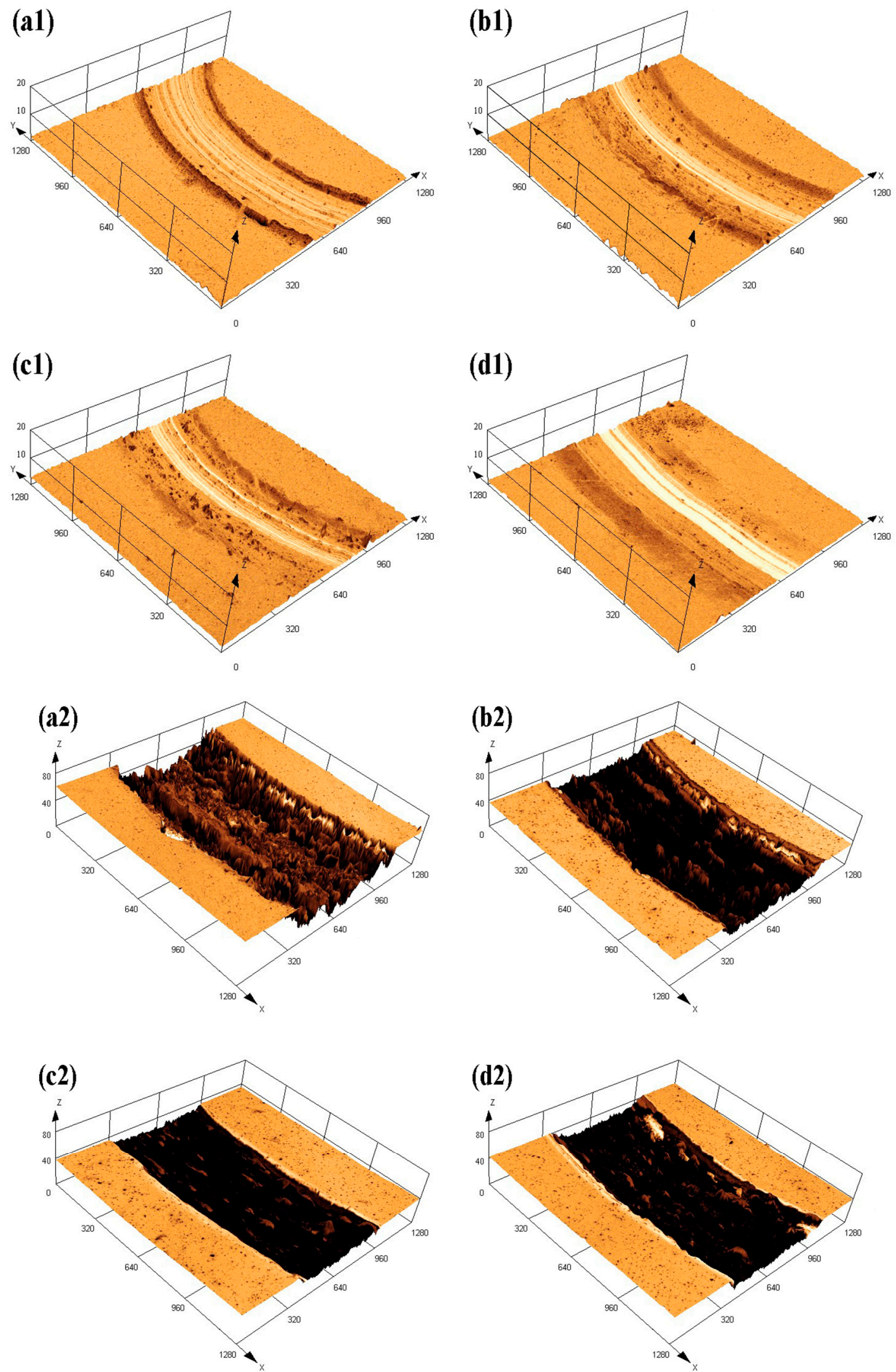

Figure 11. The 3D graphs of the wear tracks of WC/WCN coatings deposited with different nitrogen gas flow observed by LCMS: (a) $0 \mathrm{sccm}$ (b) $8 \mathrm{sccm}$ (c) $16 \mathrm{sccm}$ (d) $24 \mathrm{sccm}$ at $25^{\circ} \mathrm{C}(\mathbf{a} 1, \mathbf{d 1})$ and $400{ }^{\circ} \mathrm{C}(\mathbf{a} 2, \mathrm{~d} 2)$. 


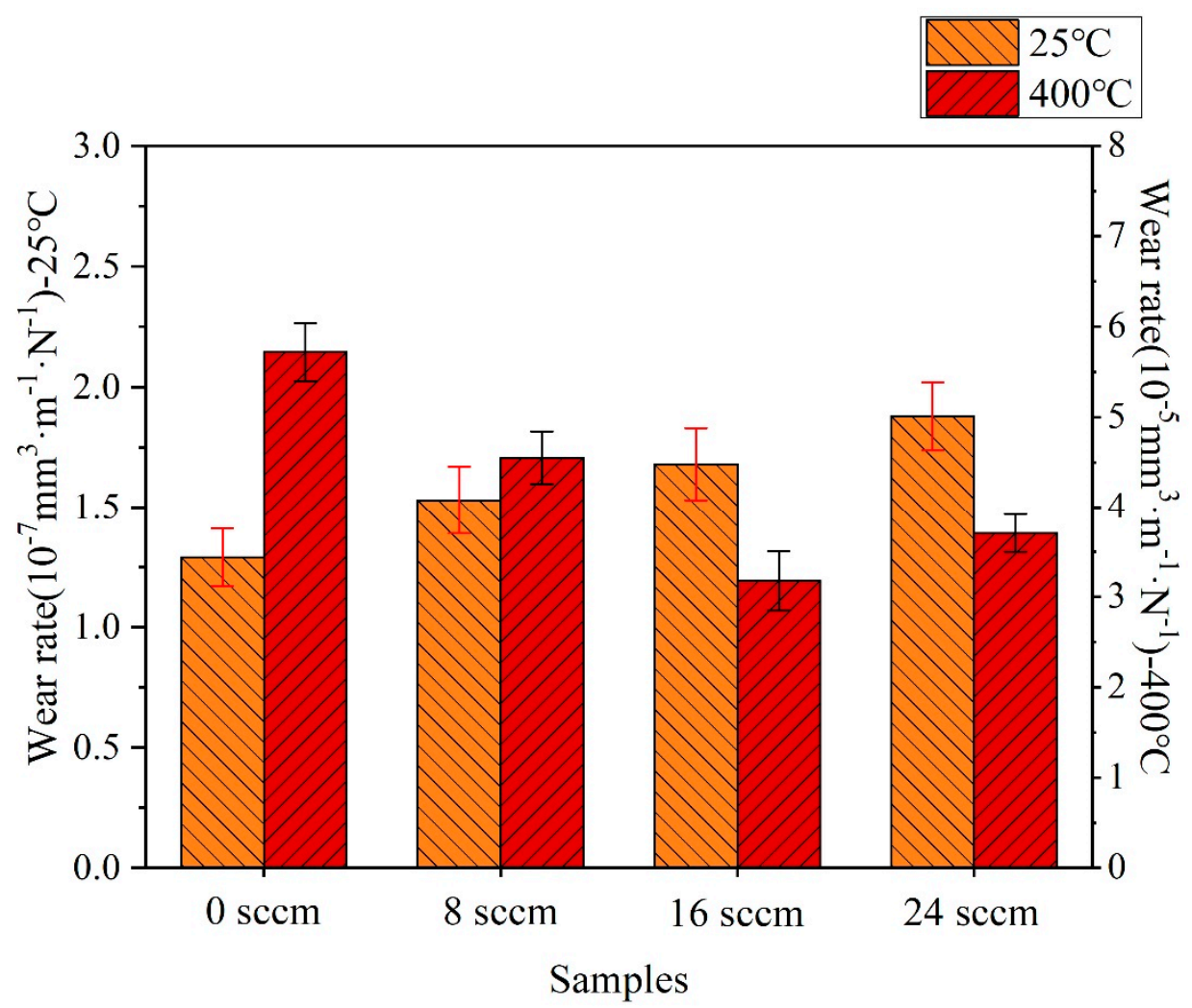

Figure 12. Wear rates of $\mathrm{WC} / \mathrm{WCN}$ coatings at $25^{\circ} \mathrm{C}$ and $400{ }^{\circ} \mathrm{C}$ deposited with different nitrogen gas flow.

\section{Conclusions}

Nanostructured WC/WCN coatings with various nitrogen contents obtained by controlling the flow rate of $\mathrm{N}_{2}$ in the deposition are successfully fabricated on $\mathrm{Si}$ (100) wafers and YT 15 cemented carbides through HiPIMS technology. The discharge characteristics of HiPIMS, microstructure, mechanical properties, room temperature, and elevated temperature tribological properties of the deposited coatings as a function of the nitrogen gas flow have been investigated and compared. The most important results can be summarized as follows: With the increase of nitrogen gas flow, the peak discharge current and the intensities of optical emission spectra lines originated from the W I (W0), N I (N0), Ar I $(\mathrm{Ar} 0)$ and $\mathrm{Ar}$ II (Ar+) first increase and then decrease, while the emission intensity of the $\mathrm{C}$ I (C0) lines declines. Pure WC coating exhibits multiple orientations of (101), (102), and (110), respectively, characteristic of rhombohedral $\beta-\mathrm{W} 2 \mathrm{C}$ phase. The average grain size decreases from $8.9 \mathrm{~nm}$ to $6.4 \mathrm{~nm}$ with the $\mathrm{N}_{2}$ flow rate increasing from $0 \mathrm{sccm}$ to $24 \mathrm{sccm}$. The XPS spectra indicate the intensities of $\mathrm{C}=\mathrm{N}, \mathrm{W}-\mathrm{N}, \mathrm{W}-\mathrm{C}-\mathrm{N}$ and $\mathrm{N}-\mathrm{O}$ peaks increase, while the intensity of $\mathrm{C}-\mathrm{W}$ peak decreases. Further, more W-N bonds are formed in WCN coatings with higher $\mathrm{N}$ concentration. The deposition rate of the coatings first increases, then decreases. The cross-sectional morphologies of deposited coatings change from slight columnar type to a typically dense and featureless structure, and the surface roughness decreases from Ra $11.6 \mathrm{~nm}$ at $0 \mathrm{sccm}$ to Ra $5.7 \mathrm{~nm}$ at $24 \mathrm{sccm}$. The hardness and elastic modulus of WC/WCN coatings first increase, then decrease. The maximum values are 35.6 GPa and $476.5 \mathrm{GPa}$ at $16 \mathrm{sccm}$, respectively. All the hardness and elastic modulus values of $\mathrm{WCN}$ coatings are higher than those of the pure WC coating. The tribological properties at room temperature $\left(25^{\circ} \mathrm{C}\right)$ deteriorate slightly with the increases of $\mathrm{N}_{2}$ flow rate while tribological properties at high temperature $\left(400^{\circ} \mathrm{C}\right)$ improve significantly first, then deteriorate slightly with the increasing $\mathrm{N}_{2}$ flow rate according to images of the wear 
track and the wear rates of the coatings. The best high-temperature tribological property is obtained when the nitrogen flow rate is $16 \mathrm{sccm}$.

Author Contributions: Conceptualization, W.X.; Data curation, Y.Y.; Funding acquisition, S.H. and L.W.; Investigation, S.F. and L.W.; Methodology, Y.W.; Project administration, L.W.; Resources, W.X. and L.W.; Software, Y.W.; Supervision, L.W.; Visualization, Y.W.; Writing-original draft, W.H.; Writing-review \& editing, M.H. and L.W. All authors have read and agreed to the published version of the manuscript.

Funding: This work was supported by Guangdong Enterprise Science and Technology Commissioner Project (GDKTP2020065800), Guangdong Special Support Program (2019BT02C629), Science and Technology Programs of Guangdong Province (2020B010184001, 2018A030313660), Special Fund for Scientific and Technological Innovation Strategy of Guangdong Province (No. 2018B090902003), Science and Technology Programs of Guangzhou (201904010261, 202007020008) and GDAS' Project of Science \& Technology (2021GDASYL-20210103064).

Institutional Review Board Statement: Not applicable.

Informed Consent Statement: Not applicable.

Data Availability Statement: Not applicable.

Conflicts of Interest: The authors declare no conflict of interest.

\section{References}

1. Benedetti, M.; Fontanari, V.; Torresani, E.; Girardi, C.; Giordanino, L. Investigation of lubricated rolling sliding behaviour of WC/C, WC/C-CrN, DLC based coatings and plasma nitriding of steel for possible use in worm gearing. Wear 2017, 378-379, 106-113. [CrossRef]

2. Rivera-Tello, C.D.; Broitman, E.; Flores-Ruiz, F.J.; Jimenez, O.; Flores, M. Mechanical properties and tribological behavior at micro and macro-scale of WC/WCN/W hierarchical multilayer coatings. Tribol. Int. 2016, 101, 194-203. [CrossRef]

3. Pu, J.B.; He, D.Q.; Wang, L.P. Effects of WC phase contents on the microstructure, mechanical properties and tribological behaviors of WC/a-C superlattice coatings. Appl. Surf. Sci. 2015, 357, 2039-2047. [CrossRef]

4. Pouraliakbar, H.; Khalaj, G.; Gomidželović, L.; Khalaj, M.J.; Nazerfakhari, M. Duplex ceramic coating produced by low temperature thermo-reactive deposition and diffusion on the cold work tool steel substrate: Thermodynamics, kinetics and modeling. Ceram. Int. 2015, 41, 9350-9360. [CrossRef]

5. Khalaj, G.; Khalaj, M.J. Application of ANFIS for modeling of layer thickness of chromium carbonitride coating. Neural Comput. Appl. 2014, 24, 685-694. [CrossRef]

6. Pourasad, J.; Ehsani, N.; Khalifesoltani, S.A. Preparation and characterization of $\mathrm{SiO}_{2}$ thin film and $\mathrm{SiC}$ nanofibers to improve of graphite oxidation resistance. J. Eur. Ceram. Soc. 2016, 36, 3947-3956. [CrossRef]

7. Ehrburger, P.; Lahaye, J.; Bourgeois, C. Characterization of carbon-carbon composites-II: Oxidation behaviour. Carbon 1981, 19, 7-10. [CrossRef]

8. Banerji, A.; Bhowmick, S.; Alpas, A.T. High temperature tribological behavior of W containing diamond-like carbon (DLC) coating against titanium alloys. Surf. Coat. Technol. 2014, 241, 93-104. [CrossRef]

9. Shen, Y.-Q.; Zhang, Z.-Q.; Liao, B.; Wu, X.-Y.; Zhang, X.; Hua, Q.-S.; Bao, M.-Y. Tribocorrosion performance of Nitrogen-doped diamond like carbon coating by high power impulse magnetron sputtering technique. Acta Phys. Sin. Chin. Ed. 2020, 69, 108101.

10. Bootkul, D.; Supsermpol, B.; Saenphinit, N.; Aramwit, C.; Intarasiri, S. Nitrogen doping for adhesion improvement of DLC film deposited on Si substrate by Filtered Cathodic Vacuum Arc (FCVA) technique. Appl. Surf. Sci. 2014, 310, 284-292. [CrossRef]

11. Corona-Gomez, J.; Shiri, S.; Mohammadtaheri, M.; Yang, Q. Adhesion enhancement of DLC on CoCrMo alloy by diamond and nitrogen incorporation for wear resistant applications. Surf. Coat. Technol. 2017, 332, 120-127. [CrossRef]

12. Ju, H.; Wang, R.; Ding, N.; Yu, L.; Xu, J.; Ahmed, F.; Zuo, B.; Geng, Y. Improvement on the oxidation resistance and tribological properties of molybdenum disulfide film by doping nitrogen. Mater. Des. 2019, 186, 108300. [CrossRef]

13. Wang, L.; Li, L.; Li, G.; Ma, Q. Improved Adhesion of TiAlSiN Nanocomposite Coatings on Cemented Carbide Substrate by Pre-Implantation. Coatings 2019, 9, 209. [CrossRef]

14. Wang, L.; Jin, J.; Zhu, C.; Li, G.; Kuang, X.; Huang, K. Effects of HiPIMS pulse-length on plasma discharge and on the properties of WC-DLC coatings. Appl. Surf. Sci. 2019, 487, 526-538. [CrossRef]

15. Syed, B.; Hsu, T.W.; Chaar, A.B.B.; Polcik, P.; Kolozsvari, S.; Håkansson, G.; Rosen, J.; Johnson, L.J.S.; Zhirkov, I.; Andersson, J.M.; et al. Effect of varying $\mathrm{N}_{2}$ pressure on DC arc plasma properties and microstructure of TiAlN coatings. Plasma Sources Sci. Technol. 2020, 29, 095015. [CrossRef]

16. Safi, I. Recent aspects concerning DC reactive magnetron sputtering of thin films: A review. Surf. Coat. Technol. 2000, 127, 203-218. [CrossRef] 
17. Fekete, M.; Bernátová, K.; Klein, P.; Hnilica, J.; Vašina, P. Evolution of discharge parameters and sputtered species ionization in reactive HiPIMS with oxygen, nitrogen and acetylene. Plasma Sources Sci. Technol. 2019, 28, 025011. [CrossRef]

18. Lin, J.; Sproul, W.D.; Wei, R.; Chistyakov, R. Diamond like carbon films deposited by HiPIMS using oscillatory voltage pulses. Surf. Coat. Technol. 2014, 258, 1212-1222. [CrossRef]

19. Peng, Y.L.; Guo, C.Q.; Lin, S.S.; Shi, Q.; Wei, C.B.; Su, Y.F.; Wu, Y.Q.; Tang, P.; Zhu, X.G.; Dai, M.J. Effects of working pressure on structure and properties of Al-containing amorphous carbon films prepared by high-power impulse magnetron sputtering. J. Alloys Compd. 2019, 816, 152587. [CrossRef]

20. Zuo, X.; Zhang, D.; Chen, R.; Ke, P.; Odén, M.; Wang, A. Spectroscopic investigation on the near-substrate plasma characteristics of chromium HiPIMS in low density discharge mode. Plasma Sources Sci. Technol. 2020, 29, 0150013. [CrossRef]

21. Yarin, A.L.; Rovagnati, B.; Mashayek, F.; Matsoukas, T. A reaction model for plasma coating of nanoparticles by amorphous carbon layers. J. Appl. Phys. 2006, 99, 064310. [CrossRef]

22. Guillaumot, A.; Lapostolle, F.; Dublanche-Tixier, C.; Oliveira, J.C.; Billard, A.; Langlade, C. Reactive deposition of Al-N coatings in Ar/N2 atmospheres using pulsed-DC or high power impulse magnetron sputtering discharges. Vacuum 2010, 85, 120-125. [CrossRef]

23. Lu, C.-Y.; Diyatmika, W.; Lou, B.-S.; Lee, J.-W. Superimposition of high power impulse and middle frequency magnetron sputtering for fabrication of CrTiBN multicomponent hard coatings. Surf. Coat. Technol. 2018, 350, 962-970. [CrossRef]

24. Zhao, H.; Ni, Z.; Ye, F. Effect of carbon content on structure and properties of WCN coatings prepared by RF magnetron sputtering. Surf. Coat. Technol. 2016, 287, 129-137. [CrossRef]

25. Su, Y.D.; Hu, C.Q.; Wen, M.; Wang, C.; Liu, D.S.; Zheng, W.T. Effects of bias voltage and annealing on the structure and mechanical properties of $\mathrm{WC}_{0.75} \mathrm{~N}_{0.25}$ thin films. J. Alloys Compd. 2009, 486, 357-364. [CrossRef]

26. Ospina, R.; Escobar-Rincón, D.; Arango, P.J.; Restrepo-Parra, E.; Jurado, J.F. Structural and chemical composition analysis of WCN produced by pulsed vacuum arc discharge. Surf. Coat. Technol. 2013, 232, 96-100. [CrossRef]

27. Olaya, J.; Rodil, S.; Muhl, S.; Sánchez, E. Comparative study of chromium nitride coatings deposited by unbalanced and balanced magnetron sputtering. Thin Solid Film. 2005, 474, 119-126. [CrossRef]

28. Kaoumi, D.; Motta, A.T.; Birtcher, R.C. A thermal spike model of grain growth under irradiation. J. Appl. Phys. 2008, 104, 073525. [CrossRef]

29. Luo, H.; Gao, F.; Billard, A. Tunable microstructures and morphology of zirconium films via an assist of magnetic field in HiPIMS for improved mechanical properties. Surf. Coat. Technol. 2019, 374, 822-832. [CrossRef]

30. Pradhan, A.A.; Shah, S.I.; Unruh, K.M. Reactive sputter deposition of alumina thin films using a hollow cathode sputtering source. Rev. Sci. Instrum. 2002, 73, 3841-3845. [CrossRef]

31. Sánchez-López, J.C.; Dominguez-Meister, S.; Rojas, T.C.; Colasuonno, M.; Bazzan, M.; Patelli, A. Tribological properties of TiC/a-C:H nanocomposite coatings prepared via HiPIMS. Appl. Surf. Sci. 2018, 440, 458-466. [CrossRef]

32. Wang, W.; Pelenovich, V.O.; Yousaf, M.I.; Yan, S.; Bin, H.; Wang, Z.; Tolstogouzov, A.B.; Kumar, P.; Yang, B.; Fu, D.J. Microstructure, mechanical and tribological properties of WC/a-C:H coatings deposited by cathodic arc ion-plating. Vacuum 2016, 132, 31-39. [CrossRef]

33. Hinnen, C.; Imbert, D.; Siffre, J.M.; Marcus, P. An in situ XPS study of sputter-deposited aluminium thin films on graphite. Appl. Surf. Sci. 1994, 78, 219-231. [CrossRef]

34. Qureshi, A.; Shah, S.; Pelagade, S.; Singh, N.L.; Mukherjee, S.; Tripathi, A.; Despande, U.P.; Shripathi, T. Surface modification of polycarbonate by plasma treatment. J. Phys. Conf. Ser. 2010, 208, 012108. [CrossRef]

35. Czyzniewski, A. Deposition and some properties of nanocrystalline WC and nanocomposite WC/a-C:H coatings. Thin Solid Film. 2003, 433, 180-185. [CrossRef]

36. Jiang, P.C.; Chen, J.S.; Lin, Y.K. Structural and electrical characteristics of W-N thin films prepared by reactive rf sputtering. J. Vac. Sci. Technol. 2003, 21, 616-622. [CrossRef]

37. Shen, Y.G.; Mai, Y.W.; Mckenzie, D.R.; Zhang, Q.C.; McFall, W.D.; McBride, W.E. Composition, residual stress, and structural properties of thin tungsten nitride films deposited by reactive magnetron sputtering. J. Appl. Phys. 2000, 88, 1380-1388. [CrossRef]

38. Moulder, J.F.; Stickle, W.F.; Sobol, P.E.; Bomben, K.D. Handbook of X-Ray Photoelectron Spectroscopy: A Reference Book of Standard Spectra for Identification and Interpretation of XPS Data; Moulder, J.F., Chastain, J., Eds.; Physical Electronics: Chanhassen, MN, USA, 1993.

39. Wang, C.; Tao, Q.; Li, Y.; Ma, S.; Dong, S.; Cui, T.; Wang, X.; Zhu, P. Excellent mechanical properties of metastable c-WN fabricated at high pressure and high temperature. Int. J. Refract. Met. Hard Mater. 2017, 66, 63-67. [CrossRef]

40. Tang, J.-F.; Lin, C.-Y.; Yang, F.-C.; Tsai, Y.-J.; Chang, C.-L. Effects of nitrogen-argon flow ratio on the microstructural and mechanical properties of AlCrN coatings prepared using high power impulse magnetron sputtering. Surf. Coat. Technol. 2020, 386, 125484. [CrossRef]

41. Snyders, R.; Gouttebaron, R.; Dauchot, J.P.; Hecq, M. Mass spectrometry diagnostic of dc magnetron reactive sputtering. J. Anal. At. Spectrom. 2003, 18, 618-623. [CrossRef]

42. Yu, L.; Zhao, H.; Xu, J. Mechanical, tribological and corrosion performance of WBN composite films deposited by reactive magnetron sputtering. Appl. Surf. Sci. 2014, 315, 380-386. [CrossRef] 